\title{
5 Research Square

\section{Nematicidal activities of aureothin and alloaureothin from endophytic bacteria, Streptomyces sp. AE170020, against the pine wood nematode, Bursaphelenchus xylophilus}

\section{Min-Kyoung Kang}

Korea Research Institute of Bioscience and Biotechnology (KRIBB)

Jong-Hoon Kim

Korea Research Institute of Bioscience and Biotechnology (KRIBB)

Min-Jiao Liu

Korea Research Institute of Bioscience and Biotechnology (KRIBB)

Chun-Zhi Jin

Korea Research Institute of Bioscience and Biotechnology (KRIBB)

Dong-Jin Park

Korea Research Institute of Bioscience and Biotechnology (KRIBB)

Junheon Kim

National Institute of Forest Science

Kwang-Hee Son ( $\nabla$ sonkh@kribb.re.kr)

Korea Research Institute of Bioscience and Biotechnology (KRIBB)

Chang-Jin Kim

Korea Research Institute of Bioscience and Biotechnology (KRIBB)

\section{Research Article}

Keywords: Pine wilt disease, Bursaphelenchus xylophilus, nematicidal activity, aureothin, alloaureothin

Posted Date: July 19th, 2021

DOl: https://doi.org/10.21203/rs.3.rs-690115/v1

License: (c) (i) This work is licensed under a Creative Commons Attribution 4.0 International License. Read Full License 


\section{Abstract}

Endophytic bacteria, a rich source of bioactive secondary metabolites, are ideal candidates for environmentally benign agents. In this study, an endophytic strain, Streptomyces sp. AE170020, was isolated and selected for the purification of nematicidal substances based on its high nematicidal activity. Two highly active components, aureothin and alloaureothin, were identified, and their chemical structures were determined using spectroscopic analysis. Both compounds suppressed the growth, reproduction, and behavior of Bursaphelenchus xylophilus. In in vivo experiments, the extracts of strain Streptomyces sp. AE170020 effectively suppressed the development of pine wilt disease in four-year-old plants of Pinus densiflora. The potency of secondary metabolites isolated from endophytic strains suggests applications in controlling Bursaphelenchus xylophilus and opens an avenue for further research on exploring bioactive substances against the pine wood nematode.

\section{Introduction}

Pine trees are one of the most important tree species in global ecosystems. They are not only a predominant component of natural reserves, parks, and urban ornamental landscapes but are also a valuable source of high-value timber carpentry items. The most serious threat to pine forests worldwide is pine wilt disease (PWD) caused by the pine wood nematode (PWN), Bursaphelenchus xylophilus. B. xylophilus is a quarantined plant parasitic nematode of the Aphelenchoidoidea superfamily and belongs to clade 10 tylenchida $^{1}$.. Native to North America, it was first introduced to Japan at the beginning of the 20 th century ${ }^{2}$. Since then, PWN has spread further to China, South Korea, Portugal, and thereafter to Europe $^{3,4}$. When pine trees are infected with pathogenic PWN, some dynamic host responses are induced by the nematode infection, such as the generation of superoxide anions, the development of vacuoles in ray parenchyma cells to capacity, and a dramatic increase in lipid peroxide levels, resulting in host mortality ${ }^{5}$. PWD, a disease that has reportedly caused significant damage to forestry, ecologies of the affected countries, and local economies, is becoming a matter of concern in several continents.

The current means of controlling PWNs rely on chemical nematicides, which are expensive, inefficient and have adverse impacts on the environment and human health ${ }^{6}$. Indeed, the use of beneficial bacteria and bacterial nematicides has spawned intense interest in the development of safer alternatives for PWN management ${ }^{7,8}$. However, many problems remain regarding the bacterial control of nematodes, including the relative scarcity of nematicidal bacteria. Only a few bacteria have been reported to possess activity against nematodes and to show potential for the biological control of nematodes ${ }^{9-11}$. Identifying novel nematicidal bacteria has become urgent for the bacterial control of nematodes and is of vital practical and economic significance.

Endophytic bacteria that reside in the tissues of living plants and establish a symbiotic relationship with the host are relatively unstudied and potent sources of novel natural products for application in medicine, industry, and agriculture ${ }^{12-14}$. Several reports have investigated bacterial endophytes as possible agents 
against $\mathrm{PWNs}{ }^{15,16}$. These bacteria kill nematodes by different mechanisms, including by mobilizing plant defenses and producing an array of secondary metabolites and enzymes.

The community of endophytic bacteria in Pinus spp. has been investigated using several methods, such as cultivation-based methodologies, biochemical characterization of the isolates by BIOLOG phenotypic assay ${ }^{17}$, and molecular approaches ${ }^{18-20}$. Strains belonging to the genera Bacillus, Paenibacillus, and Pseudomonas were isolated from several pine tree species, and some of these bacteria were found to produce siderophores ${ }^{18}$ or have the ability to fix nitrogen ${ }^{19,20}$. However, bacteria associated with Pinus spp. have rarely been explored with regard to their nematicidal activity against $B$. xylophilus ${ }^{21}$. Therefore, the objectives of this study are (i) to isolate the nematicidal substances from Streptomyces sp.

AE170020, an endophytic bacteria isolated from root tissues of pine tree; (ii) to investigate the effects of active substances on B. xylophilus, and (iii) to evaluate the disease control efficacy of the strain as a biocontrol agent in vivo.

\section{Materials And Methods}

General instruments. The ${ }^{1} \mathrm{H}$ nuclear magnetic resonance (NMR) and ${ }^{13} \mathrm{C}$ NMR spectra were obtained on a Bruker Biospin Avance 400 spectrometer with tetramethylsilane (TMS) as the internal standard. Electrospray ionization-mass spectrometry (ESI-MS) was performed on an Agilent $6430 \mathrm{LC} / \mathrm{MS} / \mathrm{MS}$ and a $1100 \mathrm{LC} / \mathrm{MS}$ spectrometer. The high-performance liquid chromatography (HPLC) system comprised a Hitachi Model L-2130 pump, L-2400 UV detector, and YMC J'sphere ODS H-80 column (4 mm, $20 \times 150$ $\mathrm{mm}$, YMC Co., Ltd).

Chemicals. Highly pure, chemical-grade $n$-Hexane, chloroform $\left(\mathrm{CHCl}_{3}\right)$, ethyl acetate (EtOAc), $n$-buthanol ( $n-\mathrm{BuOH})$, and acetone were purchased from Samchun Pure Chemical Co., Ltd., Korea. Dimethyl sulfoxide (DMSO, 99.9\%, spectrophotometric grade), trifluoroacetic acid (TFA, for HPLC, $\geq 99.0 \%$ ), proteinase K, abamectin, propylene glycol monomethyl ether (PGME), propylene glycol (PG),thiobarbituric acid, trichloroacetic acid, and $\mathrm{Na}_{2} \mathrm{CO}_{3}$ were obtained from Sigma-Aldrich Chemie $\mathrm{GmbH}$, Steinheim, Germany. $\mathrm{MeOH}$ and water for HPLC analysis were purchased from Duksan Pure Chemicals Co., Ltd., Korea. FolinCiocalteu's phenol reagent was obtained from Merck KGaA, Darmstadt, Germany. Tris buffer and gallic acid were purchased from Bioneer Corp and MP Biomedicals, Korea, respectively.

Isolation and molecular identification of Strain AE170020. Strain AE170020 was isolated from root

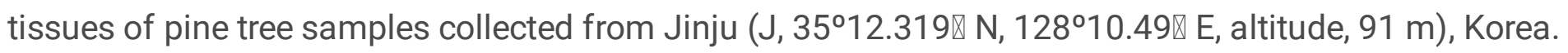
Pine tree samples were obtained with permission from the National Institute of Forest Science. We complied with relevant institutional, national and international guidelines and laws in the study of the use of pine samples.

Plant samples were washed with an ultrasonic step (160 W, $30 \mathrm{~min}$ ) to remove the surface soils and epiphytes. The washed plants were put into sterilized Petri dishes with aseptic filter paper to remove the surface water. After drying, plants were subjected to a seven-step surface sterilization procedure: 
immersion in $0.1 \%$ Tween 20 for $1 \mathrm{~min}$, followed by a 6 -min wash in $5 \%$ sodium hypochlorite, a 10 -min wash in $2.5 \%$ sterilized sodium thiosulfate, three washes in sterile water, a 4-min wash in $70 \%$ ethanol, five washes in sterile distilled water, and a final rinse in $5 \%$ sodium bicarbonate for $10 \mathrm{~min}$. Samples were then put into $2 \mathrm{ml}$ sterile tubes and grinded using liquid nitrogen and then put onto TWYE media $(0.25 \mathrm{~g}$ Yeast extract, $0.5 \mathrm{~g} \mathrm{~K}_{2} \mathrm{HPO}_{4}$, agar, $1 \mathrm{~L} \mathrm{DW}$ ). After six weeks of inoculation, the isolate was selected and purified. Genomic DNA was extracted, and the 16S rRNA gene was amplified using polymerase reaction. The resulting 16S rRNA gene sequence was compared with the curated sequences from EzBioCloud (http://www.ezbiocloud.net/) and a phylogenetic tree was built with the neighbor-joining method.

Acquisition of pine wood nematode (PWD). B. xylophilus were supplied by the National Institute of Forest Science, Seoul, Korea. B. xylophilus were reared on a lawn of Botrytis cinerea cultured on potato dextrose agar (Difco, BD) medium in the dark at $25^{\circ} \mathrm{C}$ for 7 days; nematodes were then extracted using the Baermann funnel method for bioassay ${ }^{22}$. To obtain bacteria-free PWNs, nematodes were extracted and transferred to Petri dishes containing sterile distilled water to allow egg laying for $3 \mathrm{~h}$. Most eggs adhered to the bottom surface of the Petri dish and were gently washed with distilled water many times to remove the hatched nematodes. Then, $15 \% \mathrm{H}_{2} \mathrm{O}_{2}$ was added into the Petri dish, which was rinsed for $60 \mathrm{~min}$ at $25^{\circ} \mathrm{C}$; next, the Petri dish was washed with sterile water three times. Eggs were then resuspended in sterile distilled water and allowed to hatch. The PWN J2 ${ }_{S}$ that were almost synchronized after $24 \mathrm{~h}$ at $25^{\circ} \mathrm{C}$ were obtained and used for mortality assays. The $\mathrm{J} 2 \mathrm{~S}$ were transferred onto a culture of $B$. cinerea on a PDA plate, and $\mathrm{J} 3_{\mathrm{S}}$ and $\mathrm{J} 4_{\mathrm{S}}$ /adults were collected at $30 \mathrm{~h}$ and $78 \mathrm{~h}$ after feeding re-initiation, respectively.

Detecting nematicidal activity of strain Streptomyces sp. AE170020. The strain was inoculated into the GSS broth (20 g glucose; $10 \mathrm{~g}$ soluble starch; $25 \mathrm{~g}$ soybean meal; $1 \mathrm{~g}$ beef extract; $4 \mathrm{~g}$ yeast extract; $2 \mathrm{~g}$ $\mathrm{NaCl} ; 0.25 \mathrm{~g} \mathrm{~K}_{2} \mathrm{HPO}_{4} ; 2 \mathrm{~g} \mathrm{CaCO}_{3}$, and $1 \mathrm{~L} \mathrm{DW}$ ) for $36 \mathrm{~h}$. Two percent of the seed was transferred to a 500 $\mathrm{mL}$ flask containing $50 \mathrm{~mL}$ of GSS broth and incubated on a rotary shaker at $150 \mathrm{rpm}$ at $28^{\circ} \mathrm{C}$ for $1-10$ days. The culture of strain AE170020 was then centrifuged at 13,000 rpm for $10 \mathrm{~min}$ to separate the broth and cells. The resultant supernatant was aseptically transferred to sterile tubes and used for a nematicidal bioassay, as described by Gao et al. (2016), with some modification ${ }^{23}$. Briefly, $50 \mu \mathrm{L}$ of the supernatant and bacteria-free L2s of B. xylophilus $(n=30-40)$ specimens were added to each well of a 96-well tissue culture plate. Later, $100 \mu \mathrm{g} \mathrm{mL}^{-1}$ streptomycin was also added to each well to inhibit bacterial contamination, and GSS broth was used as a control.

Detecting the stability of nematicidal activity of Streptomyces sp. AE170020 culture. The stability of strain AE170020 was detected following the method of Gao et al. (2016). The supernatant of strain Streptomyces sp. AE170020 was treated with $20 \mathrm{mg} \mathrm{mL}^{-1}$ of proteinase $\mathrm{K}$ at $37^{\circ} \mathrm{C}$ for $30 \mathrm{~min}$ or boiled at $100^{\circ} \mathrm{C}$ for $5 \mathrm{~min}$. Thereafter, the nematicidal activity of the supernatant was detected. This supernatant was also adjusted to $\mathrm{pH}$ values from 1.0 to 11.0 by $\mathrm{HCl}$ or $\mathrm{NaOH}$ solution and incubated for $2 \mathrm{~h}$; the nematicidal activity of the supernatant was then detected after the $\mathrm{pH}$ value was re-adjusted to 7.0 . 
Fermentation, extraction, and purification of nematicidal substances from Streptomyces sp. AE170020 culture. Strain cultures were prepared as described above and centrifuged at 6,000 rpm for $30 \mathrm{~min}$. The collected supernatant was then sequentially extracted with an equivalent volume of $n$-hexane, $\mathrm{CHCl}_{3}$, EtOAc, and $n-\mathrm{BuOH}$. The mycelium of strain AE170020 was extracted with acetone, sonicated for 30 min, and kept overnight. All extractions were performed thrice. Different solvent layers were concentrated in vacuo to obtain the dry extracts. The nematicidal activity of the extracts was determined: $2 \mu \mathrm{L}$ of the solvent extract of Streptomyces sp. AE170020 was dissolved in DMSO and added to the 96-well plate, containing approximately $40-50 \mathrm{~L} 2 \mathrm{~s}$ nematodes in $98 \mu \mathrm{L}$ of sterile water. The final concentrations of solvent extracts were $0.0625,0.1250,0.2500,0.500$, and $1.000 \mathrm{mg} \mathrm{mL}^{-1}$, and $2 \mu \mathrm{L}$ of DMSO was used as a control. Acetone extracts, which showed the highest activity against PWN, were used for further purification.

The fractions extracted by acetone were applied on a silica gel column and eluted with a stepwise $n$ hexane/acetone gradient of increasing polarity. Fractions were checked on a TLC plate, and those with similar TLC patterns were pooled for nematicidal activity testing. One of the fractions that showed high nematicidal activity was applied on a Sephadex LH-20 column and eluted with $\mathrm{MeOH}$. Nematicidal activity of subfractions was tested and combined as above. Further, active subfractions were purified with preparative TLC plates, and two active compounds were obtained. HPLC with a gradient solvent system of aqueous $\mathrm{MeOH}$, containing $0.04 \%$ TFA, as a mobile phase was used to check the purity of the compound.

Different developmental stages of B. xylophilus mortality assay. Two of the most potent purified compounds, alloaueohtin and aureothin, were further explored for their effects on the different stages, reproduction, growth, and behavior of $B$. xylophilus. Different developmental stages of nematode were prepared as previously described, and L2s were exposed to the two compounds at final concentrations of $0.05,0.10,0.20,0.50,1.00,2.00$, and $4.00 \mathrm{~g} \mathrm{~mL}^{-1}$; $\mathrm{L} 3 \mathrm{~s}$ and $\mathrm{L} 4 \mathrm{~s}$ /adults were exposed to concentrations of $0.25,0.50,1.00,2.50,5.00$, and $10.00 \mu \mathrm{g} \mathrm{mL}^{-1}$. The commercial nematicide, abamectin, at the same concentrations and DMSO were used as positive and solvent controls, respectively.

The treated plates were stored in the dark at $25^{\circ} \mathrm{C}$, and the mortality of PWNs was recorded after $24-\mathrm{h}$ treatment by visualization under a light microscope (Nikon, SMZ-U). The $\mathrm{LC}_{50}$ values of active compounds at different life stages were estimated. Mortality was defined based on the observation of motility, a visibly moving nematode was marked as alive, and nematodes that failed to respond after several touches were marked as dead. The bioassays were performed three times in triplicate. Mortality was calculated according to the following formula: mortality $(\%)=$ dead juveniles/total juveniles $\times 100$.

Effects of compounds on the locomotion behavior of B. xylophilus. In liquids, a single movement of the stylet knob forwards and then backwards to its original position was called "thrashing" 24 . To assess the impact of alloaureothin and aureothin on B. xylophilus mortality, thrashing of L3s nematode was assayed. Thrashing rate was scored for $1 \mathrm{~min}$ at the following time points: 2,6 , and $24 \mathrm{~h}$ in the presence of two compounds at the indicated concentrations $\left(1.0,2.5\right.$ and $\left.5.0 \mu \mathrm{g} \mathrm{mL}^{-1}\right)$. Control assays were 
conducted in the presence of DMSO or abamectin, and all assays were conducted at $22^{\circ} \mathrm{C}$. Two trials were performed for this experiment, and six numbers of surviving nematode in each treatment were used to test the thrashing behavior.

Nematode population inhibition assay. A population inhibition assay was conducted according to the method described by Cheng et al. (2017) with some modification. Briefly, adult nematodes ( 500) were initially treated with alloaureothin and aureothin at concentrations of 0.5 and $1.0 \mu \mathrm{g} \mathrm{mL}^{-1}$, and incubated for $24 \mathrm{~h}$ at $22^{\circ} \mathrm{C}$. After $24 \mathrm{~h}, 10$ female and male nematodes were randomly selected and placed on a PDA plate fully covered with Botrytis cinerea and allowed to grow. When the $B$. cinerea has been completely consumed by nematodes in control plates, nematodes were extracted from plates using distilled water. The recovered nematodes were then serially diluted and numbers of nematodes in $100 \mu \mathrm{L}$ suspensions were counted. The reproduction rates $\left(P_{f} / P_{i}, P_{f}\right.$, final nematode population; $P_{i}$, initial nematode population) were calculated. The experiment was conducted twice, with three replicates per treatment.

Nematode hatch inhibition assay. Nematode eggs were obtained as above and used for the embryonic lethality tests. Experiments were conducted using established procedures ${ }^{24}$. Egg suspensions were exposed to alloaureothin and aureothin at final concentrations of $20,15,10,5,2,1,0.5$, and $0.1 \mu \mathrm{gL}^{-1}$. Two microliters of DMSO and abamectin at the same concentration were served as negative and positive, respectively. Plates were incubated at $22^{\circ} \mathrm{C}$ and nematodes of the L2s stage were scored after $48 \mathrm{~h}$. The hatching rate was calculated according to the following formula: Hatching rate $(\%, \mathrm{HR})=$ [juveniles / (eggs + juveniles $) \times 100]$. Each treatment was repeated in three wells, and the experiment was repeated three times.

Egg deposition assay. One-day-old female nematodes in the presence of alloaureothin, aureothin or abamectin ( $5 \mathrm{ug} \mathrm{mL}^{-1}$ ) were used in the egg deposition assay according to an established protocol ${ }^{24}$. $B$. xylophilus (about 100 numbers) were treated with compound for $24 \mathrm{~h}$ in the 96 -well plates. Approximately 10 male and 10 female nematodes were then selected randomly and transferred to Petri dishes and allowed to lay eggs for $24 \mathrm{~h}$. The eggs laid by a single female were then recorded and the nematodes inside the female body were also imaged. The experiments were performed two times with six repetitions.

Suppression of pine wilt disease under pot condition. Injection of active substances into pine trees was performed to evaluate the control efficacy in vivo, as previously described ${ }^{25}$. The pot experiments were conducted in a greenhouse at Korea Research Institute of Bioscience and Biotechnology (Daejeon, Korea) and Pinus densiflora were transferred to a greenhouse for at least one month prior to the pot test and watered every other day and fertilized if necessary. The average temperature of the greenhouse was $25 \pm$ $5^{\circ} \mathrm{C}$. Acetone extracts of strain AE170020 were prepared as described above and dissolved using DPPT solvent (20\% DMSO, $20 \%$ propylene glycol monomethyl ether, $50 \%$ propylene glycol, and $10 \%$ Tween-20). The solution of abamectin in DPPT solvent served as a positive control. Holes were made in the trunk of pine trees (average height, $124 \mathrm{~cm}$; average basal diameter, $1.4 \mathrm{~cm}$ ) by using an electric drill about $5 \mathrm{~cm}$ above the ground level. Then, $200 \mu \mathrm{L}$ of strain extract was injected into holes at different concentrations, and holes were immediately covered with parafilm. The final concentration of the acetone extract was 7.2 
$\mathrm{mg}, 3.6 \mathrm{mg}$, and $1.8 \mathrm{mg}$ per tree and abamectin was $3.6 \mathrm{mg}$ per tree. Control plants were injected with the DPPT solution. Inoculations of $B$. xylophilus were performed one week after the injection of chemicals in the trunk. B. xylophilus were reared on $B$. cinerea and extracted; they were then washed with distilled water at least five times to remove any fungal hyphae present. Final nematode density in the suspension was adjusted to about 20,000 nematodes per $\mathrm{mL}$. A hole in the trunk of each pine tree was made approximately $20 \mathrm{~cm}$ above the soil. A $0.1 \mathrm{~mL}$ aliquot of the nematode suspension (containing about 2,000 nematodes: a mixture of adults and juveniles) was pipetted into the holes and the holes were covered with parafilm. Control plants were also wounded but distilled water was used instead of the PWN solution. Pine trees were watered three times a week. Three runs with five replicates for each treatment were conducted. External symptoms of pine trees were visually assessed at 15, 30, 45, and 60 days after the inoculation and results were recorded at 60 days.

Sample collection and processing. Sixty days after inoculation, three pine trees from each treatment in one trial were randomly selected and collected. Plants were cut immediately above the ground. Needles and the twigs were removed, and the stems were chopped into small pieces. Stems were immediately weighed and used for nematode quantification. The remaining stems and leaves were stored at $-80^{\circ} \mathrm{C}$ for chemical analysis.

Nematode quantification in inoculated trees. The nematode population was measured using established procedures ${ }^{26}$. Five grams of the stem pieces were weighed and transferred into gauze equipped in the upper part of a $50 \mathrm{~mL}$ falcon tube. The plant tissues were then immersed in water for $24 \mathrm{~h}$, and after that the gauze and plants were gently removed from tubes and allowed to precipitate for $12 \mathrm{~h}$. Nematodes were mostly located at the bottom of the falcon tube after the precipitation and the upper water was removed to make a final volume of $10 \mathrm{~mL}$. Then, $100 \mu \mathrm{L}$ of the extracted nematodes was transferred into 96-well tissue plates, and live nematodes were counted under a light microscope. Nematode density was expressed as the number of nematodes in the stem per gram of wood. The data of each treatment were generated from three trees and obtained in triplicate.

Chemical analysis. Chemical analyses were performed on leaf tissues (total chlorophyll, total polyphenolics, and lipid peroxidation) and stem tissues (water content). Leaves collected as previously described were used for chlorophyll quantification. The extraction and determination of the chlorophyll content were performed as per the method described by ${ }^{26}$. Briefly, needles were homogenized with liquid nitrogen, and samples (about $0.1 \mathrm{~g}$ ) were extracted with $10 \mathrm{~mL}$ of cold acetone/Tris buffer (80:20 vol:vol, $\mathrm{pH}=7.8$ ). The samples were incubated at $4^{\circ} \mathrm{C}$ for $72 \mathrm{~h}$, and the tubes were centrifuged at $13,000 \mathrm{rpm}$ for 5 $\min$. The absorbances were then recorded at 537, 647, and $663 \mathrm{~nm}$ in a UV/visible spectrophotometer (Pharmacia Biotech, Ultraspec 3000). The amount of chlorophyll was calculated as follows: total chlorophyll concentration in the extract $\left(\mathrm{mmol} \mathrm{mL}^{-1}\right)=\left(0.001373 A_{663}-0.000897 A_{537}-0.003046 A_{647}\right)$ $+\left(0.02405 A_{647}-0.004305 A_{537}-0.005507 A_{663}\right)$.

The concentration of total soluble phenolics was determined using the protocol described by Ainsworth et al $(2007)^{27}$. Needles were ground with liquid nitrogen; about $100 \mathrm{mg}$ of leaves was extracted with $95 \%$ 
methanol and sonicated for $15 \mathrm{~min}$. Samples were then gently shook and allowed to react overnight in the dark at room temperature. Later, $200 \mu \mathrm{L}$ of $10 \%$ (vol/vol) Folin-Ciocalteu's phenol reagent was added to $100 \mu \mathrm{L}$ of the methanolic extract. The solution was mixed thoroughly and allowed to stand for 5 min, after which $800 \mu \mathrm{L}$ of $700 \mathrm{mM} \mathrm{Na}{ }_{2} \mathrm{CO}_{3}$ was added, and the tubes were incubated at ambient room temperature for $2 \mathrm{~h}$. Next, $150 \mu \mathrm{L}$ of each sample solution was loaded on a 96-well microplate and the absorbance was measured at $760 \mathrm{~nm}$ with a spectrophotometric microplate reader (VERSAmax ${ }^{\mathrm{TM}}$ ). The total phenolic concentration was calculated from the gallic acid calibration curve. Data were expressed as gallic acid equivalents (GA)/g of extracts averaged from each treatment.

To gain insights about plant oxidative stress and cell damage, lipid peroxidation was measured. The level of lipid peroxidation in tissues was determined in terms of the malondialdehyde (MDA) content by the method of Nunes et al (2015). After homogenization with liquid nitrogen, about $0.1 \mathrm{~g}$ of leaf sample was extracted with $10 \mathrm{~mL} 0.5 \%$ thiobarbituric acid in $20 \%$ trichloroacetic acid. The sample was then vortexed thoroughly and incubated at $100^{\circ} \mathrm{C}$ for $30 \mathrm{~min}$. Next, reaction solutions were immediately transferred to ice for $5 \mathrm{~min}$ and then centrifuged at 4,000 rpm for $15 \mathrm{~min}$. The absorbance was monitored at 450, 532, and $600 \mathrm{~nm}$ in a UV/visible spectrophotometer. Calculation of MDA was based on the following formula: MDA concentration $(\mu \mathrm{mol} \mathrm{L}-1)=6.45\left(A_{532}-A_{600}\right)-0.56 A_{450}$.

Specific water content was used as a proxy for water stress, which is usually associated with PWD. For water content determination, each wood sample was oven dried for $72 \mathrm{~h}$, and the relative water content was evaluated through the following formula: relative water content $(\%)=$ (fresh weight - dry weight) / fresh weight $\times 100$. All the chemical data were obtained from six trees and three samples per tree.

Statistical analysis. Data analyses were performed using SPSS 18.0 software (SPSS Inc.), and the LC $_{50}$ values were determined via a probit analysis. Values are expressed as mean \pm standard deviation (SD) unless indicated otherwise. The data were compared using analysis of variance (ANOVA) followed by a post-hoc test, as appropriate. Significant differences were determined according to thresholds of $* p<$ $0.05 ;{ }^{* \star} p<0.01$, and ${ }^{* \star \star} p<0.001$. All charts and figures generated in this study were constructed using GraphPad Prism version 8.0.2.

\section{Results}

Molecular and phylogenetic analysis. The identification of 16S rRNA gene sequence using EzTaxon server revealed that strain AE170020 belongs to the genus Streptomyces and it shared the highest (98.6\%) sequence similarity with Streptomyces stramineus. The neighbor-joining phylogenetic trees analysis showed that strain AE170020 lies in a subclade in the tree with species of genera Streptomyces (Fig. 1).

Characterization of nematicidal activity of Streptomyces sp. AE170020. As shown in Fig. 2, the 3-d to 10$\mathrm{d}$ fermentation supernatant of strain AE170020 had evident activity against $B$. xylophilus, with mortality ranging from $62.8 \pm 2.5 \%$ to $94.2 \pm 0.8 \%$. The highest mortality was observed when $B$. xylophilus was 
exposure to 5-d and 6-d fermentation broths. The broth of GSS medium led to a modest mortality rate of $6.7 \pm 0.6 \%$ (Fig. 2).

The nematicidal substances of strain AE170020 were also analyzed for their stability at different pH values. It was found that the supernatant of strain AE170020 exhibited high nematicidal activity within a $\mathrm{pH}$ range of 4.0-11.0. However, the nematicidal activity slightly decreased at $\mathrm{pH} 4.0$ and 5.0 , and no mortality was observed in strong acidic environments ( $\mathrm{pH} 1.0-3.0)$ (Fig. 3A).

The supernatant of strain AE170020 was also analyzed for its stability towards protease digestion. After hydrolysis with protease $\mathrm{K}$, the supernatant of strain AE170020 also showed high nematicidal activity with a mortality of $91.6 \pm 2.9 \%$ against $B$. xylophilus (Fig. 3B). Therefore, we speculated that strain AE170020 produces some extracellular substances to kill the nematode and the nematicidal substances of the fermentation broth are not protein but could be secondary metabolites instead.

Nematicidal activity of strain AE170020 extracts. The mortality rates of different solvent partitions were assessed as shown in Fig. 4. The extracts of different solvents clearly display a concentration-dependent nematicidal activity against $B$. xylophilus. The phase extracted by acetone showed the highest nematicidal activity with $89.2 \pm 2.2 \%$ mortality at a concentration of $1.0 \mathrm{mg} \mathrm{mL}^{-1}$, followed by the hexane extract. The extracts of $\mathrm{CHCl}_{3}$ and EtOAc also exhibited nematicidal activities relative to the control group with a mortality rate of $5.7 \pm 0.7 \%$. However, $\mathrm{BuOH}$ extract and DW layer had no activity.

Purification and identification of bioactive compound. ${ }^{1} \mathrm{H} N M R\left(400 \mathrm{MHz}, \mathrm{CDCl}_{3}\right)$ and ${ }^{13} \mathrm{C} \mathrm{NMR}(100 \mathrm{MHz}$, $\mathrm{CDCl}_{3}$ ) data for the two compounds are listed in Table 1. On the basis of spectroscopic data and comparison with the values reported in the literature, the two compounds were assigned as alloaureothin and aureothin, respectively (Fig. 5).

Table 1

${ }^{1} \mathrm{H}(400 \mathrm{MHz})$ and ${ }^{13} \mathrm{C}(100 \mathrm{MHz}) \mathrm{NMR}$ data of compound 1 and 2 in $\mathrm{CDCl}_{3}$.

\begin{tabular}{|lll|}
\hline Chemical & \multicolumn{1}{c|}{$\begin{array}{l}\text { Concentration } \\
\text { (mg per seedling) }\end{array}$} & Estimated number of nematodes \\
& & \\
\hline Acetone extract of & 7.2 & $350 \pm 53^{\mathrm{a}}$ \\
strain AE170020 & 3.6 & $387 \pm 84^{\mathrm{a}}$ \\
\hline & 1.8 & $720 \pm 107^{\mathrm{c}}$ \\
\hline Abamectin & 3.6 & $433 \pm 184^{\mathrm{a}}$ \\
\hline Untreated & - & $3426 \pm 576^{\mathrm{b}}$ \\
\hline $\begin{array}{l}\text { 1NNematode population was measured } 60 \text { days after inoculation. Values represent the mean } \pm \text { SD. } \\
\text { Means in the same column followed by the same letters are not significantly different. }\end{array}$ \\
\hline
\end{tabular}


Effects of alloaureothin and aureothin on different developmental stages of B. xylophilus. Alloaureothin and aureothin showed highly significant activity against L2s, L3s, and L4s/adults of $B$. xylophilus, and as expected, the two compounds concentration-dependently killed B. xylophilus. Among these, the L2s stage is the most sensitive to the two compounds, followed by L3s and L4s/adults stages, and this sensitivity pattern is similar to that observed with the positive control, abamectin (Fig. 6). After 24-h exposure, the $\mathrm{LC}_{50}$ values of alloaureothin on different life stages of B. xylophilus: (L2s, $\mathrm{L} 3 \mathrm{~s}$, and L4s/adults) were 0.83 , 1.10 , and $1.47 \mu \mathrm{g} \mathrm{mL}^{-1}$, respectively, and the values of aureothin were $0.81,1.15$, and $1.54 \mu \mathrm{g} \mathrm{mL}^{-1}$ respectively (Fig. 6A, B, C). Compared with abamectin, both compounds showed higher nematicidal activity against $B$. xylophilus at all tested life stages, and the two compounds showed similar mortality rates against $B$. xylophilus.

\section{Alloaureothin and aureothin suppressed the thrashing potential of nematode. After being treated with} alloaureothin and aureothin, nematode thrashing frequencies were decreased, and this decrease was time-dependent and concentration-dependent. Nematode thrashing frequencies were significantly reduced by alloaureothin ( $14 \pm 4$ ), aureothin $(8 \pm 3)$, and abamectin $(9 \pm 3)$ at a concentration of $1 \mu \mathrm{g} \mathrm{mL}^{-1}$ as compared with the solvent-treated group (54 \pm 4 ) and non-treated control (55 \pm 3 ) after $24 \mathrm{~h}$ (Fig. 7B). Upon exposure to the active compounds at a concentration of $5.0 \mu \mathrm{g} \mathrm{mL}^{-1}$, nematodes almost had no movement after 24-h treatment (Fig. 7A).

Effects of alloaureothin and aureothin on the reproductive traits of B. xylophilus. The mycelia of Botrytis cinerea were almost completely consumed by nematodes after 7 days in the non-treated plates and the DMSO-treated group exhibited a similar clearance zone to the non-treated plates (Fig. 8Ai, ii). In contrast, in the plates treated with two active compounds, clearance zones were clearly reduced (Fig. 8Aiii, iv, v, vi). Alloaureothin and aureothin were found to decrease the mean nematode numbers to $1.3 \times 10^{5} \pm 0.5,1.2 \times$ $10^{5} \pm 0.7$ at the concentration of $0.5 \mu \mathrm{g} \mathrm{mL}^{-1}$, while the values were $0.3 \times 10^{5} \pm 0.1$ and $0.2 \times 10^{5} \pm 0.1$ at the concentration of $1 \mu \mathrm{g} \mathrm{mL}^{-1}$ compared with non-treated controls $\left(2.5 \times 10^{5} \pm 0.4\right)$ (Fig. 8B).

Alloaureothin and aureothin affected the hatching and fecundity of nematode. The effect of active compounds on reproductive activity was measured in vitro by direct contact. The results suggested that the hatching rate of $B$. xylophilus was significantly inhibited by the test compounds in a dose-dependent manner. Non-treated and solvent controls presented a hatching rate of $92.1 \pm 2.1 \%$ and $87.5 \pm 3.3 \%$ respectively, whereas alloaureothin and aureothin at a concentration of $20 \mu \mathrm{g} \mathrm{mL}^{-1}$ treated nematode eggs almost failed to hatch. In addition, both compounds exhibited a significantly lower hatching rate compared with abamectin (Fig. 9A).

Furthermore, two active compounds also adversely influenced the fecundity of gravid adults at the concentration of $5 \mu \mathrm{g} \mathrm{mL}^{-1}$. Eggs laid by a single female in non-treatment and DMSO-treated were $12 \pm 3$ and $12 \pm 2$, respectively. However, the values were reduced to $3 \pm 1,2 \pm 1$, and $6 \pm 1$ by alloaureothin, aureothin, and abamectin (Fig. 9B). Microscopic imaging also revealed the inability of female nematodes to lay eggs, leading to the accumulation of eggs inside nematodes (Fig. 9C). 
Suppression of pine wilt disease under pot condition. Successful nematode infection in pine trees is visualized by the presence of needle discoloration, and these visual symptoms were registered to understand and compare the effect of compounds on tree survival. As shown in Table 2, after inoculation with B. xylophilus, $90 \%$ of $P$. densiflora plants in the control group died after 60 days. The injection of acetone extracts of Streptomyces sp. AE170020 and abamectin into pine trees at test concentrations successfully suppressed the development of PWD in pine trees artificially infected with B. xylophilus. Remarkably, extracts of strain AE170020 exhibited 100\% control efficacy at a concentration of $7.2 \mathrm{mg}$ per tree. 
Table 2

Control efficacy of pine wilt disease in 4-year-old Pinus desiflora treated with acetone extarct of strain AE170020 under pot conditions and nematode population per gram of stem fresh weight recovered from pine trees.

\begin{tabular}{|c|c|c|c|c|}
\hline \multirow[t]{2}{*}{ Position } & \multicolumn{2}{|l|}{1} & \multicolumn{2}{|l|}{2} \\
\hline & $\delta_{H} \delta_{C}$ & & $\delta_{H} \delta_{C}$ & \\
\hline 1 & - & $164.5, \mathrm{~s}$ & - & $162.1, \mathrm{~s}$ \\
\hline 2 & - & $100.7, \mathrm{~s}$ & - & $100.1, s$ \\
\hline 3 & - & $182.8, \mathrm{~s}$ & - & $180.6, s$ \\
\hline 4 & - & $120.7, \mathrm{~s}$ & - & $120.2, s$ \\
\hline 5 & - & $157.7, \mathrm{~s}$ & - & $154.6, \mathrm{~s}$ \\
\hline 6 & $5.23(1 \mathrm{H}, \mathrm{t}, J=6.9 \mathrm{~Hz})$ & $75.0, d$ & $5.15(1 \mathrm{H}, \mathrm{t}, J=7.0 \mathrm{~Hz})$ & $73.3, d$ \\
\hline \multirow[t]{2}{*}{7} & $2.95(1 \mathrm{H}, \mathrm{dd}, J=6.4,16.6 \mathrm{~Hz})$ & \multirow[t]{2}{*}{$38.5, \mathrm{t}$} & $2.97(1 \mathrm{H}, \mathrm{dd}, J=6.4,16.0 \mathrm{~Hz})$ & \multirow[t]{2}{*}{$38.3, \mathrm{t}$} \\
\hline & $3.05(1 \mathrm{H}, \mathrm{dd}, J=7.3,16.4 \mathrm{~Hz})$ & & $3.07(1 \mathrm{H}, \mathrm{dd}, J=6.3,16.1 \mathrm{~Hz})$ & \\
\hline 8 & - & $143.5, \mathrm{~s}$ & - & $144.2, \mathrm{~s}$ \\
\hline \multirow[t]{2}{*}{9} & $4.58(1 \mathrm{H}, \mathrm{d}, J=14.5 \mathrm{~Hz})$ & \multirow[t]{2}{*}{$71.3, \mathrm{t}$} & $4.90(1 \mathrm{H}, \mathrm{d}, J=14.2 \mathrm{~Hz})$ & \multirow[t]{2}{*}{$70.1, \mathrm{t}$} \\
\hline & $4.45(1 \mathrm{H}, \mathrm{d}, J=15.0 \mathrm{~Hz})$ & & $4.75(1 \mathrm{H}, \mathrm{d}, J=14.1 \mathrm{~Hz})$ & \\
\hline 10 & $6.40(1 \mathrm{H}, \mathrm{br}, \mathrm{s})$ & $120.9, d$ & $6.21(1 \mathrm{H}, \mathrm{br}, \mathrm{s})$ & $126.0, d$ \\
\hline 11 & - & $139.8, \mathrm{~s}$ & - & $138.5, \mathrm{~s}$ \\
\hline 12 & $6.46(1 \mathrm{H}, \mathrm{br}, \mathrm{s})$ & $128.0, d$ & $6.38(1 \mathrm{H}, \mathrm{br}, \mathrm{s})$ & $128.4, d$ \\
\hline 13 & - & $146.2, \mathrm{~s}$ & - & $140.6, s$ \\
\hline 14,18 & $7.49(2 \mathrm{H}, \mathrm{d}, J=8.6 \mathrm{~Hz})$ & $130.8, \mathrm{~d}$ & $7.40(2 \mathrm{H}, \mathrm{d}, J=8.7 \mathrm{~Hz})$ & $129.6, d$ \\
\hline 15,17 & $8.15(2 \mathrm{H}, \mathrm{d}, J=8.7 \mathrm{~Hz})$ & $124.6, \mathrm{~d}$ & $8.21(2 \mathrm{H}, \mathrm{d}, J=8.8 \mathrm{~Hz})$ & $123.6, d$ \\
\hline 16 & - & $147.4, s$ & - & $146.1, \mathrm{~s}$ \\
\hline 1-O-Me & $3.97(3 \mathrm{H}, \mathrm{s})$ & $56.5, \mathrm{q}$ & $3.96(3 \mathrm{H}, \mathrm{s})$ & $55.3, q$ \\
\hline 2-Me & $1.81(3 \mathrm{H}, \mathrm{s})$ & $7.1, \mathrm{q}$ & $1.86(3 \mathrm{H}, \mathrm{s})$ & $6.9, \mathrm{q}$ \\
\hline 4-Me & $1.97(3 \mathrm{H}, \mathrm{s})$ & $9.4, \mathrm{q}$ & $2.04(3 \mathrm{H}, \mathrm{s})$ & $9.5, \mathrm{q}$ \\
\hline 11-Me & $2.07(3 \mathrm{H}, \mathrm{s})$ & $24.3, q$ & $2.06(3 \mathrm{H}, \mathrm{s})$ & $17.7, q$ \\
\hline
\end{tabular}

Moreover, after 60 days, the nematode population was four to nine times larger in the nematode control group than in the compound-injection groups, with numbers increasing from about 2000 nematodes at inoculation to $3426 \pm 576$ nematodes per gram of plant tissue (Table 2). The lowest density of 
nematodes $(350 \pm 84)$ was recovered from pine trees treated with strain extract at the concentration of 7.2 mg per tree.

Variation of chemical traits after inoculation. It was clearly seen that injection of abamectin and acetone extract of strain AE170020 successfully prevented the reductions of water content, total chlorophyll content, and total polyphenolics (Fig. 10). PWN inoculation without acetone extract of strain 680998 significantly reduced the stem water content. After inoculation, the pine trees inoculated only with the nematodes showed relatively low water content of $18.6 \pm 4.0 \%$ (Fig. 10A). From the analysis of Fig. 10B, we can observe that the total chlorophyll content significantly decreased in the nematode-control group in comparison with the acetone extract-treated and solvent-control groups. However, the nematodeinoculated plants, either with or without extracts, showed a lower concentration of total chlorophyll than the uninoculated group plants. B. xylophilus resulted in the decrease of total polyphenolics of tissues

compared to the solvent-control group $\left(71.0 \pm 8.4 \mathrm{mg}\right.$ gallic acid Eq. $\mathrm{g}^{-1}$ leaf). The synthesis of total polyphenols in those treated with acetone substances was higher than in those inoculated only with the nematodes (Fig. 10C); however, the difference was not significant between the trees injected with acetone extract of 680998 at the concentrations of 7.2 and $3.6 \mathrm{mg}$ per tree and those in nematode-control group. As shown in Fig. 10D, the concentration of MDA in the nematode-control group was greater than in other groups, suggesting a high degree of lipid oxidative damage caused by PWN. Injection with active extracts protected pine trees from this damage. The increasing concentration of malondialdehyde (MDA) in the nematode-inoculation control group suggested a high degree of lipid oxidative damage caused by PWNs, and abamectin and strain extracts protected pine trees from this damage.

\section{Discussion}

PWD, which is caused by PWN, is one of the most destructive diseases in trees of the genus Pinus and is responsible for environmental and economic losses around the world. The frequently used nematicides to control the disease are chemical nematicides. However, these chemical nematicides reportedly have deleterious effects on human health and the environment. Biological control of the PWD using microorganisms can be a safe, cost-effective, and efficient method. Endophytes reside with plant tissues without causing any signs of disease or infections and are rich sources of bioactive substances and promising biocontrol agents because of the direct effects of metabolites to induce mortality in nematodes. Many endophytic bacteria are reported to exert nematicidal activity by producing nematicidal toxins $^{27-29}$.

In the present study, an endophytic bacteria, Streptomyces sp. AE170020, isolated from pine trees was able to kill $B$. xylophilus. We further investigated the active substances of this strain and hypothesized that some secondary metabolites may be responsible for the nematicidal activity. Subsequently, the nematicidal substances were purified by using bioassay-guided fractionation and two active compounds, alloaureothin and aureothin, were identified. Alloaureothin and aureothin, which are polypropionates with a nitro group belonging to the class of polyketides, exhibited high activity against $B$. xylophilus. Two potent compounds were previously isolated from several actinomycetes and displayed interesting 
biological activities. Aureothin isolated from the mycelium of Streptomyces thioluteus ${ }^{30}$ and Streptomyces sp. $\mathrm{MM} 23^{28}$ was reported to exhibit anti-Helicobacter, antitumor, and antifungal activities ${ }^{28}$, 31. In accordance with our results, previous studies have also shown that aureothin exerts nematicidal activity $^{30}$. Alloaureothin obtained from Streptomyces sp. MM23 was reported to exhibit growth inhibitory effects against human fibrosarcoma $\mathrm{HT} 1080$ cells with an $\mathrm{IC}_{50}$ value of $30 \mu \mathrm{M}^{28}$. In our present study, alloaureothin also showed high nematicidal activity against $B$. xylophilus.

It is important to investigate the mode of action of active compounds in the practice of nematode control, because it can provide useful information for avoiding resistance and choosing appropriate way of delivery. Further research was conducted to evaluate the effects of two potent compounds, alloaureothin and aureothin, on the growth, reproduction, and development of nematodes. The present results showed that both compounds were lethal to all developmental stages of nematode and displayed a lower $\mathrm{LC}_{50}$ value than the commercial nematicide, abamectin. In addition, the nematode population was significantly reduced by two active compounds, which supports that both compounds control the reproductive behavior of nematodes. Eggs hatchability is one of the most important parameters that affects population numbers and it has been suggested that chemicals with high embryonic lethality can be potential nematicides ${ }^{31,32}$.The two compounds obtained in our research both effectively inhibited the hatchability of nematode eggs and can be considered as potential nematicides.

The trunk injection method involves injection of pesticides directly into the tree trunk; the liquids are then transported through the plant's conductive tissues to the site of action. This method has been successfully used in biocontrol of PWD ${ }^{33}, 34$. Abamectin, a member of macrocyclic lactones, has been widely used in biocontrol of various kinds of parasitic nematodes, and several studies have shown its ability in controlling PWD ${ }^{35}, 36$. In our current study, in vivo experiments under greenhouse conditions using the trunk injection method showed that the extracts of Streptomyces sp. AE170020 and abamectin successfully suppressed the development of PWD. To monitor the multiplication of nematodes in plants with or without the active substances, pine trees in each treatment were harvested and the number of nematodes was calculated. The compounds did not kill all the nematodes but significantly reduced the total number of nematodes compared with the nematode-control group (3426 \pm 576 nematode per gram stem). These results indicate that these compounds prevented, or at least slowed, the beginning and progression of PWD. Although the two compounds isolated from different Streptomyces sp. than used herein have already been described and their biological activities have been studied, to our best knowledge, this is the first report exploring the nematicidal activity of alloaureothin and applying strain Streptomyces sp. AE170020 to the biocontrol of PWD under pot conditions.

In addition to the external symptoms, the examination of other characteristics of pine trees after treatments allowed a better assessment of the physiological impact of nematode infection and compound injection. Specific water content was used as a proxy for water stress, which is usually associated with PWD. A decrease in chlorophyll content was previously described in PWN-inoculated pine seedlings and is regarded as a symptom of the advanced stage of the PWD, which is induced by water 
deficiency in leaves ${ }^{37}$. Phenolic substances have been considered responsible for the browning of injured or pathogen-infected plant tissues, and PWD may be a result of the production of such compounds ${ }^{38}$. In the current study, acetone extract of strain Streptomyces sp. AE170020 prevented the reductions of water content, total chlorophyll, and total polyphenolics. Lipid peroxidation is an indicator of membrane cellular damage and usually occurs in plants after PWN inoculation as a result of xylem parenchyma cell necrosis and partial destruction of the cortex and phloem ${ }^{39}$. The increasing concentration of malondiadehyde in the nematode-control group suggested a high degree of lipid oxidative damage caused by PWN, and the active substances successfully protected pine trees from this damage.

Therefore, this study explored an endophytic strain, Streptomyces sp. AE170020, and its related compounds for defense against $B$. xylophilus in vitro and in vivo under greenhouse conditions. These results support the development of endophytic microorganisms as alternatives for the management of PWD. Further investigation is needed to understand the molecular mechanisms responsible for the nematicidal activity. In addition, scale-up, modification for this strain, safety evaluation, and risk assessment should be further developed to control B. xylophilus in actual agricultural applications.

\section{Declarations}

\section{Acknowledgement}

This work was supported by grants from the National Institute of Forest Science (Project No. FE07022016-11-2020 "Development of environment friendly control agents against pine wilt disease based on BT") and was supported by Korea Institute of Planning and Evaluation for Technology in Food, Agriculture and Forestry(IPET) through (Project No. 321110-4 "Crop Viruses and Pests Response Industry Technology Development") Program, funded by Ministry of Agriculture, Food and Rural Affairs(MAFRA).

\section{Conflicts of interest}

The authors declares that there is no conflict of interests regarding the publication of this article.

\section{References}

1. Kikuchi T, Cotton JA, Dalzell JJ, Hasegawa, Kanzaki KN, McVeigh P, Takanashi, T, Tsai IJ, Assefa SA, Cock PJ. Genomic insights into the origin of parasitism in the emerging plant pathogen Bursaphelenchus xylophilus. PLoS pathogens 7, e1002219. https://doi.org/10.1371/journal.ppat.1002219 (2011).

2. Mamiya Y. History of pine wilt disease in Japan. J Nematol. 20: 219 (1988).

3. Cheng XY, Cheng FX, Xu RM, Xie BY. Genetic variation in the invasive process of Bursaphelenchus xylophilus (Aphelenchida: Aphelenchoididae) and its possible spread routes in China. Heredit. 100:356. https://doi.org/ 10.1038/sj.hdy.6801082 (2008). 
4. Mota MM, Braasch H, Bravo MA, Penas AC, Burgermeister W, Metge K, Sousa E. First report of Bursaphelenchus xylophilus in Portugal and in Europe. Nematology. 1:727-

734. https://doi.org/10.1163/156854199508757 (1999).

5. Yamada T. Biochemical responses in pine trees affected by pine wilt disease. In Pine wilt disease. Springer 223-234 (2008).

6. Gowen, S. Chemical control of nematodes: efficiency and side-effects. FAO Plant Production and Protection Paper (FAO). 1997.

7. Tian BY, Yang JK, Zhang KQ. Bacteria used in the biological control of plant-parasitic nematodes: populations, mechanisms of action, and future prospects. FEMS Microbiol Ecol 61: 197-

213. https://doi.org/10.1111/j.1574-6941.2007.00349.x (2007).

8. Yu J, Du G, Li RG, Li L, Li Z, Zhou CJ, Chen CC, Guo DS. Nematicidal activities of bacterial volatiles and components from two marine bacteria, Pseudoalteromonas marina strain $\mathrm{H}-42$ and Vibrio atlanticus strain S-16, against the pine wood nematode, Bursaphelenchus xylophilus. Nematology 17:1011-1025. https://doi.org/10.1163/15685411-00002920 (2015).

9. Kerry B. Biological control of nematodes: prospects and opportunities. Plant Nematode Problems and their Control in the Near East Region 79-92 (1997).

10. Li J, Zou CG, Xu JP, Ji XL, Niu XM, Yang JK, Huang XW, Zhang KQ. Molecular mechanisms of nematode-nematophagous microbe interactions: basis for biological control of plant-parasitic nematodes. Annu Rev Phytopathol 53: 67-95. https://doi.org/10.1146/annurev-phyto-080614120336 (2015).

11. Tranier MS, Pognat-Gros J, Quiroz RDIC, González CNA, Mateille T, Roussos S. Commercial biological control agents targeted against plant-parasitic root-knot nematodes. Braz Arch Biol Technol 57:831841. https://doi.org/10.1590/S1516-8913201402540 (2014).

12. Hallmann J, Quadt-Hallmann A, Mahaffee WF, Kloepper JW. Bacterial endophytes in agricultural crops. Can J Microbiol 43:895-914. https://doi.org/10.1139/m97-131 (1997).

13. Strobel GA. Endophytes as sources of bioactive products. Microbes Infect 5:535544. https://doi.org/10.1016/s1286-4579(03)00073-x (2003).

14. Strobel G, Daisy B, Castillo U, Harper J. Natural products from endophytic microorganisms. J Nat Prod 67:257-268. https://doi.org/10.1021/np030397v (2004).

15. Zheng LJ, Li GH, Wang XB, Pan WZ, Li L, Hua L, Liu FF, Dang LZ, Mo MH, Zhang KQ. Nematicidal endophytic bacteria obtained from plants. Ann Microbiol

58:569. https://doi.org/10.1007/BF03175559 (2008).

16. Tian B, Yang J, Zhang KQ. Bacteria used in the biological control of plant-parasitic nematodes: populations, mechanisms of action, and future prospects. FEMS Microbiol Ecol 61:197213. https://doi.org/10.1111/j.1574-6941.2007.00349.x (2007).

17. Strzelczyk E, Li CY. Bacterial endobionts in the big non-mycorrhizal roots of Scots pine (Pinus sylvestris L.). Microbiol Res 155:229-232. https://doi.org/10.1016/S0944-5013(00)80037-3 (2000). 
18. Pirttilä AM, Laukkanen H, Pospiech H, Myllylä R, Hohtola A. Detection of intracellular bacteria in the buds of Scotch pine (Pinus sylvestris L.) by in situ hybridization. Appl Environ Microbiol 66:30733077. https://doi.org/10.1128/aem.66.7.3073-3077.2000 (2000).

19. Bal A, Anand R, Berge O, Chanway CP. Isolation and identification of diazotrophic bacteria from internal tissues of Pinus contorta and Thuja plicata. Can J For Res 42:807-

813. https://doi.org/10.1139/x2012-023 (2012).

20. Carrell AA, Frank AC. Pinus flexilis and Picea engelmannii share a simple and consistent needle endophyte microbiota with a potential role in nitrogen fixation. Front Microbiol 5:333. https://doi.org/10.3389/fmicb.2014.00333 (2014).

21. Ponpandian LN, Rim SO, Shanmugam G, Jeon J, Park YH, Lee SK, Bae H. Phylogenetic characterization of bacterial endophytes from four Pinus species and their nematicidal activity against the pine wood nematode. Sci Rep 9:1-11. https://doi.org/10.1038/s41598-019-48745-6 (2019).

22. Park IK, Kim J, Lee SG, Shin SC. Nematicidal activity of plant essential oils and components from ajowan (Trachyspermum ammi), allspice (Pimenta dioica) and litsea (Litsea cubeba) essential oils against pine wood nematode (Bursaphelenchus xylophilus). J Nematol 39:275 (2007).

23. Gao H, Qi G, Yin R, Zhang H, Li C, Zhao X. Bacillus cereus strain S2 shows high nematicidal activity against Meloidogyne incognita by producing sphingosine. Sci Rep

6:28756. https://doi.org/10.1038/srep28756 (2016).

24. Cheng L, Xu S, Xu C, Lu H, Zhang ZQ, Zhang DX, Mu W, Liu F. Effects of trans-2-hexenal on reproduction, growth and behaviour and efficacy against the pinewood nematode, Bursaphelenchus xylophilus. Pest Manag Sci 73: 888-895. https://doi.org/10.1002/ps.4360 (2017).

25. Liu MJ, Hwang BS, Jin CZ, Li WJ, Park DJ, Seo ST, Kim CJ. Screening, isolation and evaluation of a nematicidal compound from actinomycetes against the pine wood nematode, Bursaphelenchus xylophilus. Pest Manag Sci 75: 1585-1593. https://doi.org/10.1002/ps.5272 (2019).

26. Nunes da Silva M, Solla A, Sampedro L, Zas R, Vasconcelos MW. Susceptibility to the pinewood nematode (PWN) of four pine species involved in potential range expansion across Europe. Tree Physiol 35:987-999. https://doi.org/10.1093/treephys/tpv046 (2015).

27. Ainsworth EA, Gillespie KM. Estimation of total phenolic content and other oxidation substrates in plant tissues using Folin-Ciocalteu reagent. Nat Protoc 2:875 (2007).

28. Ueda JY, Hashimoto J, Nagai A, Nakashima T, Komaki H, Anzai K, Harayama S, Doi T, Takahashi T, Nagasawa K. New aureothin derivative, alloaureothin, from Streptomyces sp. MM23. J Antibiot (Tokyo) 60:321. https://doi.org/ 10.1038/nprot.2007.102 (2007).

29. Mekete T, Hallmann J, Kiewnick S, Sikora R. Endophytic bacteria from Ethiopian coffee plants and their potential to antagonise Meloidogyne incognita. Nematology 11:117-

127. https://doi.org/10.1163/156854108X398462 (2009).

30. Hirata Y, Nakata H, Yamada K, Okuhara K, Naito T. The structure of aureothin, a nitro compound obtained from Streptomyces thioluteus. Tetrahedron 14:252-274. https://doi.org/10.1016/S0040- 
4020(01)92175-1 (1961).

31. Taniguchi M, Watanabe M, Nagai K, Suzumura K, Suzuki K, Tanaka A. Y-Pyrone compounds with selective and potent anti-Helicobacter pylori activity. J Antibiot (Tokyo) 53:844847. https://doi.org/10.7164/antibiotics.53.844 (2000).

32. Rajasekharan SK, Lee JH, Ravichandran V, Lee J. Assessments of iodoindoles and abamectin as inducers of methuosis in pinewood nematode, Bursaphelenchus xylophilus. Sci Rep 7:113. https://doi.org/10.1038/s41598-017-07074-2 (2017).

33. Takai K, Soejima T, Suzuki T, Kawazu K. Emamectin benzoate as a candidate for a trunk-injection agent against the pine wood nematode, Bursaphelenchus xylophilus. Pest Management Science: formerly Pesticide Science 56:937-941. https://doi.org/10.1002/1526-4998(200010)56:10<937::AIDPS213>3.0.CO;2-B (2000).

34. Takai K, Suzuki T, Kawazu K. Development and preventative effect against pine wilt disease of a novel liquid formulation of emamectin benzoate. Pest Management Science: formerly Pesticide Science 59:365-370. https://doi.org/10.1002/ps.651 (2003).

35. Kwon HR, Choi GJ, Choi YH, Jang KS, Sung ND, Kang MS, Moon Y, Lee SK, Kim JC. Suppression of pine wilt disease by an antibacterial agent, oxolinic acid. Pest Manag Sci: formerly Pesticide Science. 66:634-639. https://doi.org/10.1002/ps.1920 (2010).

36. James R, Tisserat N, Todd T. Prevention of pine wilt of scots pine (Pinus sy/vestris) with systemic abamectin injections. Arboriculture and Urban Forestry 32:195 (2006).

37. Chen Y, Ye J, Wei C, Pan H. Effects of pine wood nematode (PWN) infection on water regime and metabolism of related to hosts. Acta Phytopathologica Sinica 3:201-7 (2005).

38. Futai K. Abnormal metabolites in pine wood nematode-inoculated Japanese black pine. Nematological Research (Japanese Journal of Nematology) 33:4556. https://doi.org/10.3725/jjn1993.33.2_45 (2003).

39. Yamada T. Biochemical responses in pine trees affected by pine wilt disease. In Pine wilt disease pp 223-234 Springer. https://doi.org/10.1007/978-4-431-75655-2_22 (2008).

\section{Figures}




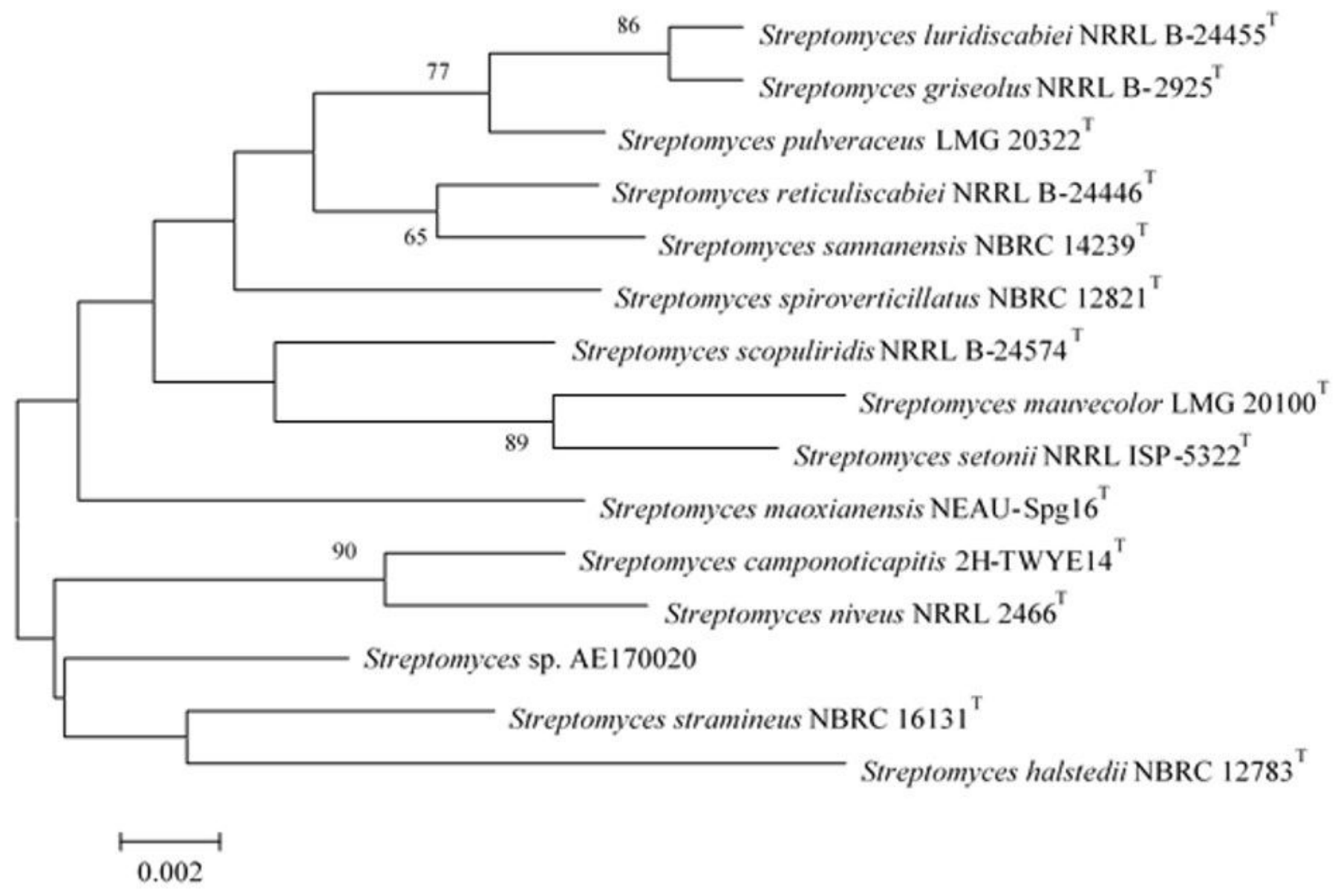

\section{Figure 1}

Phylogenetic analysis showing the relationship between strain Streptomyces sp. AE170020 and the related species. The tree was generated by neighbor-joining method of 16S rRNA gene sequences. Numbers of nodes are bootstrap values based on 1000 resampling. 


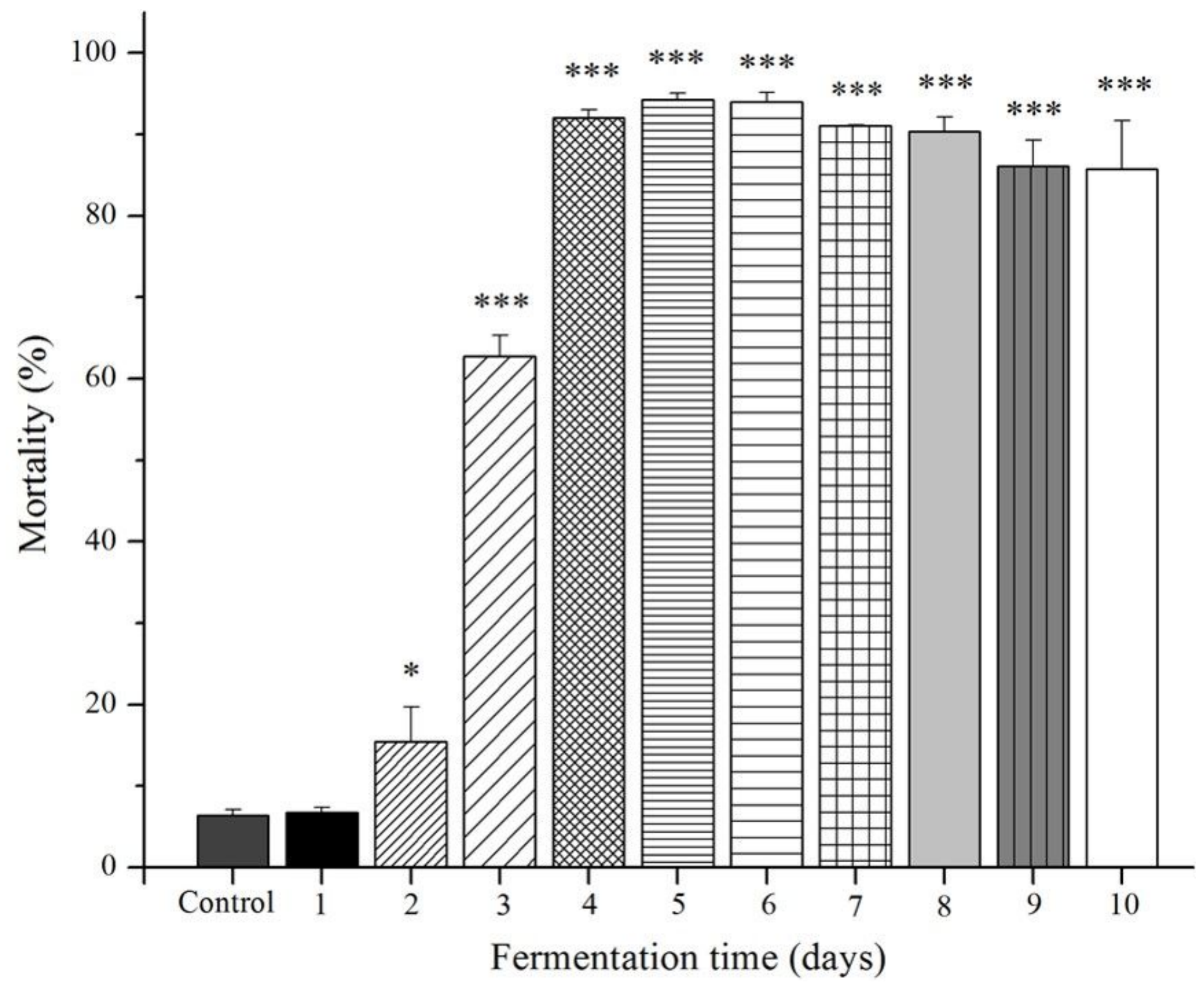

Figure 2

Effect of the fermentation time on the nematicidal activity against Bursaphelenchus xylophilus of Streptomyces sp. AE170020. Nematicidal activity was assessed by calculating the average mortality rate of nematodes treated with Streptomyces sp. AE170020 fermentation supernatant. Mortality was calculated $24 \mathrm{~h}$ after the treatment. Control, filtrate of GSS medium. Values are expressed as the mean \pm SD of two independent experiments with three replicates. 
(A)

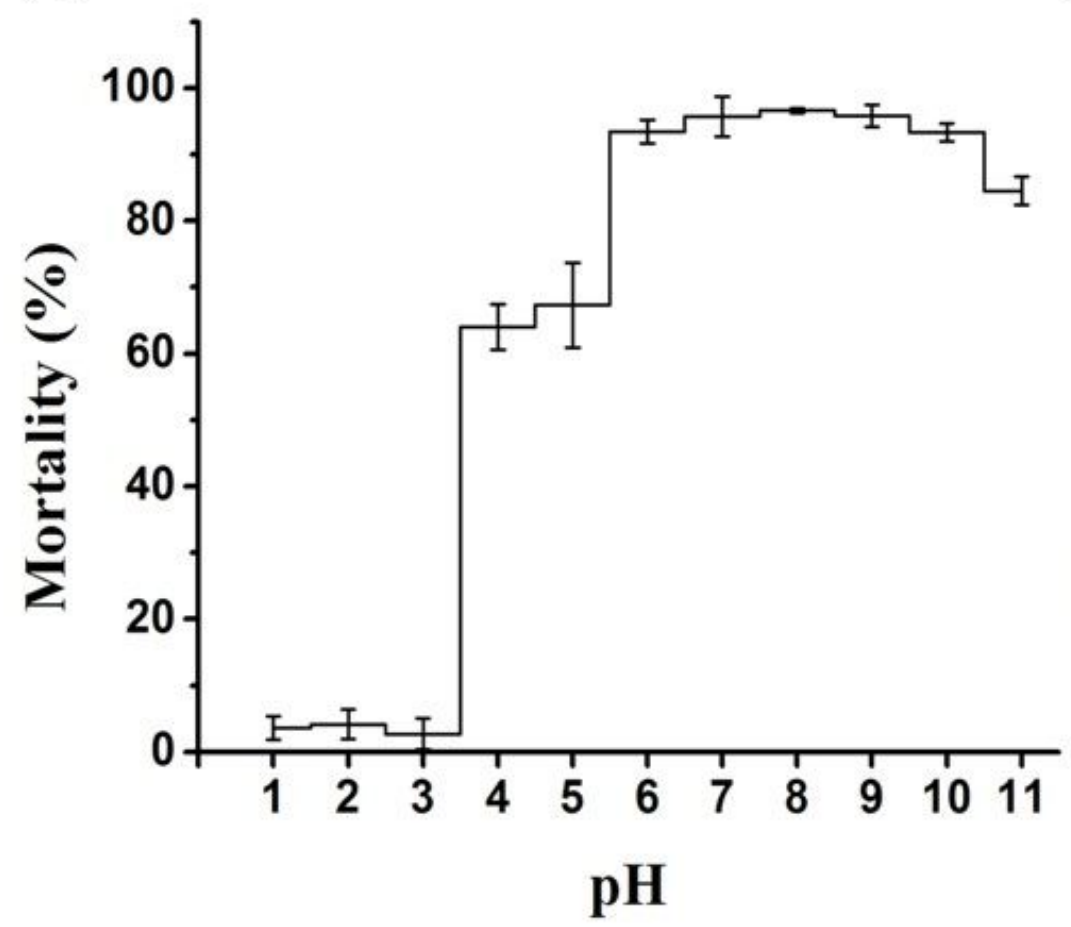

(B)

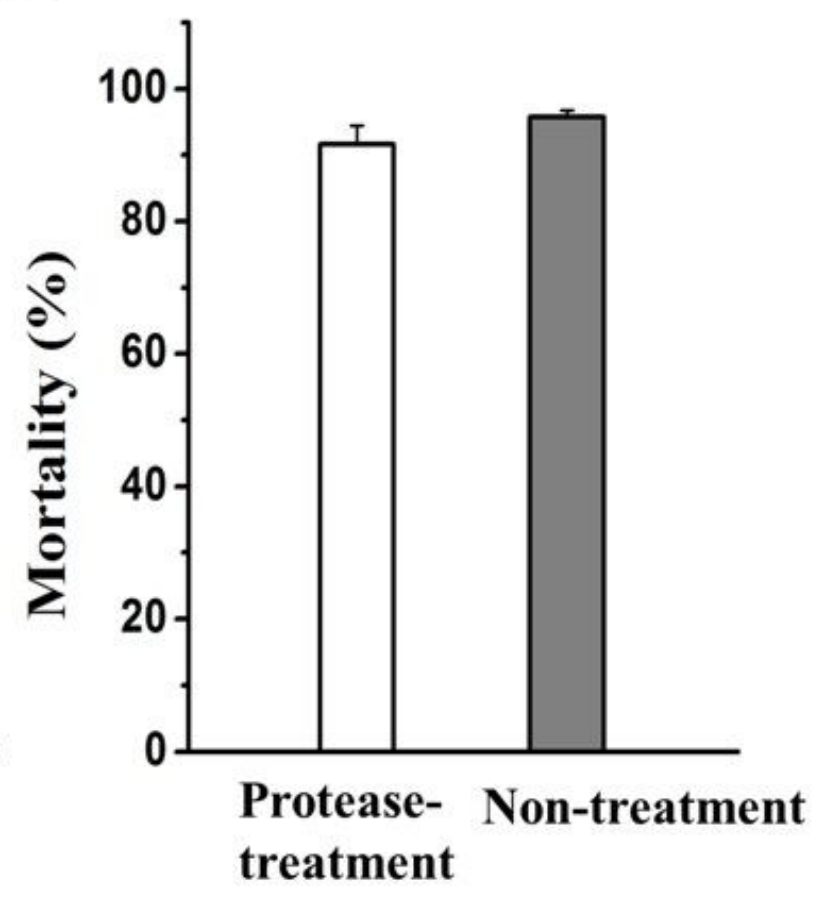

Figure 3

Nematicidal activity of Streptomyces sp. AE170020 supernatants under different conditions. (A), Nematicidal activity of Streptomyces sp. AE170020 broth between $\mathrm{pH} 1$ and 11, M9 buffer was served as control; (B), Nematicidal activity of the supernatant of Streptomyces sp. AE170020 with or without treatment with protease K. Control: supernatant of GSS medium. Data are shown as the mean \pm SD of two independent experiments with three replicates. 


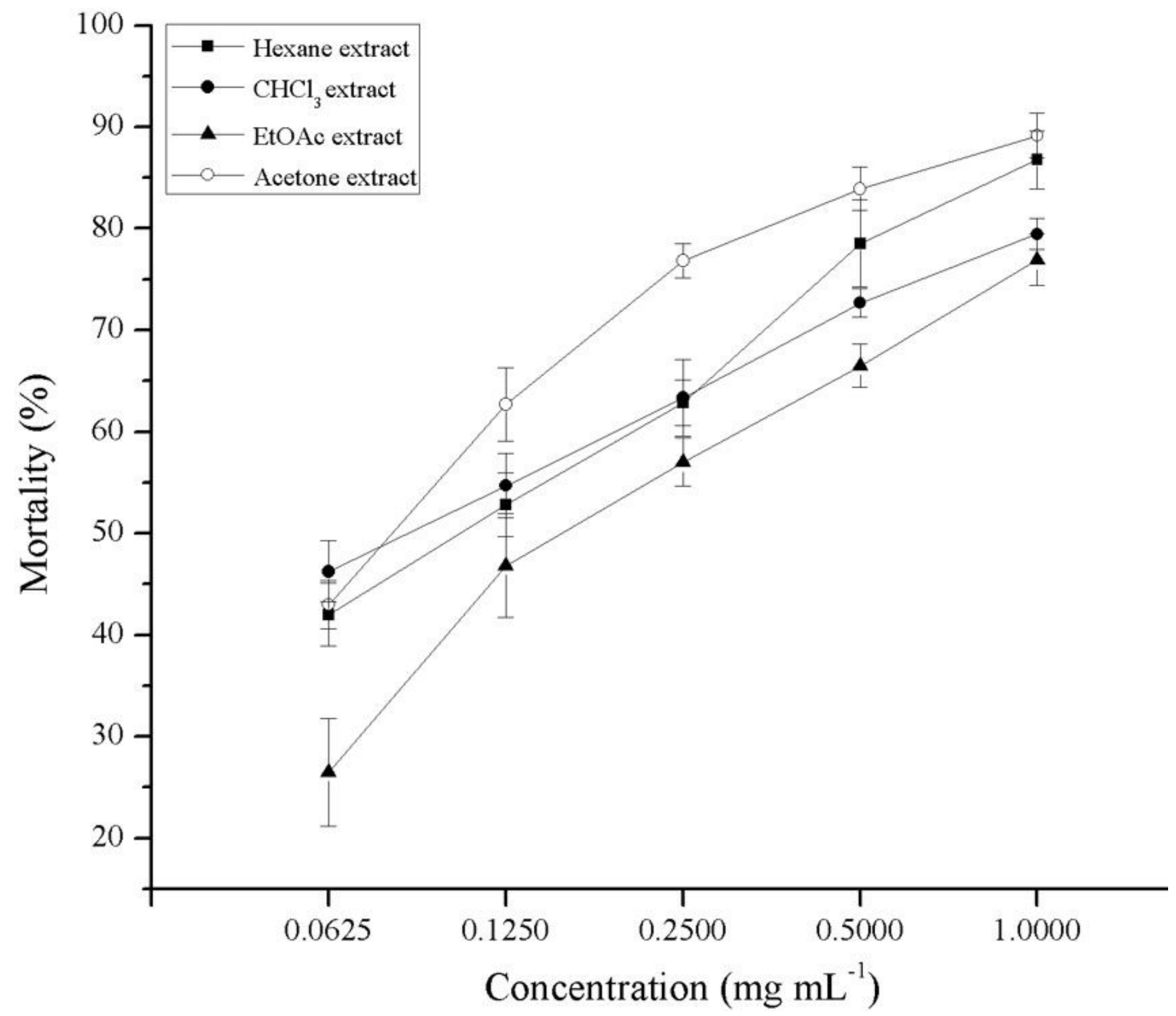

Figure 4

Nematicidal activity of solvent-partitioned extracts of Streptomyces sp. AE170020 against B. xylophilus after $24 \mathrm{~h}$ treatment. All the data are shown as the mean $\pm S D(n=9)$. 


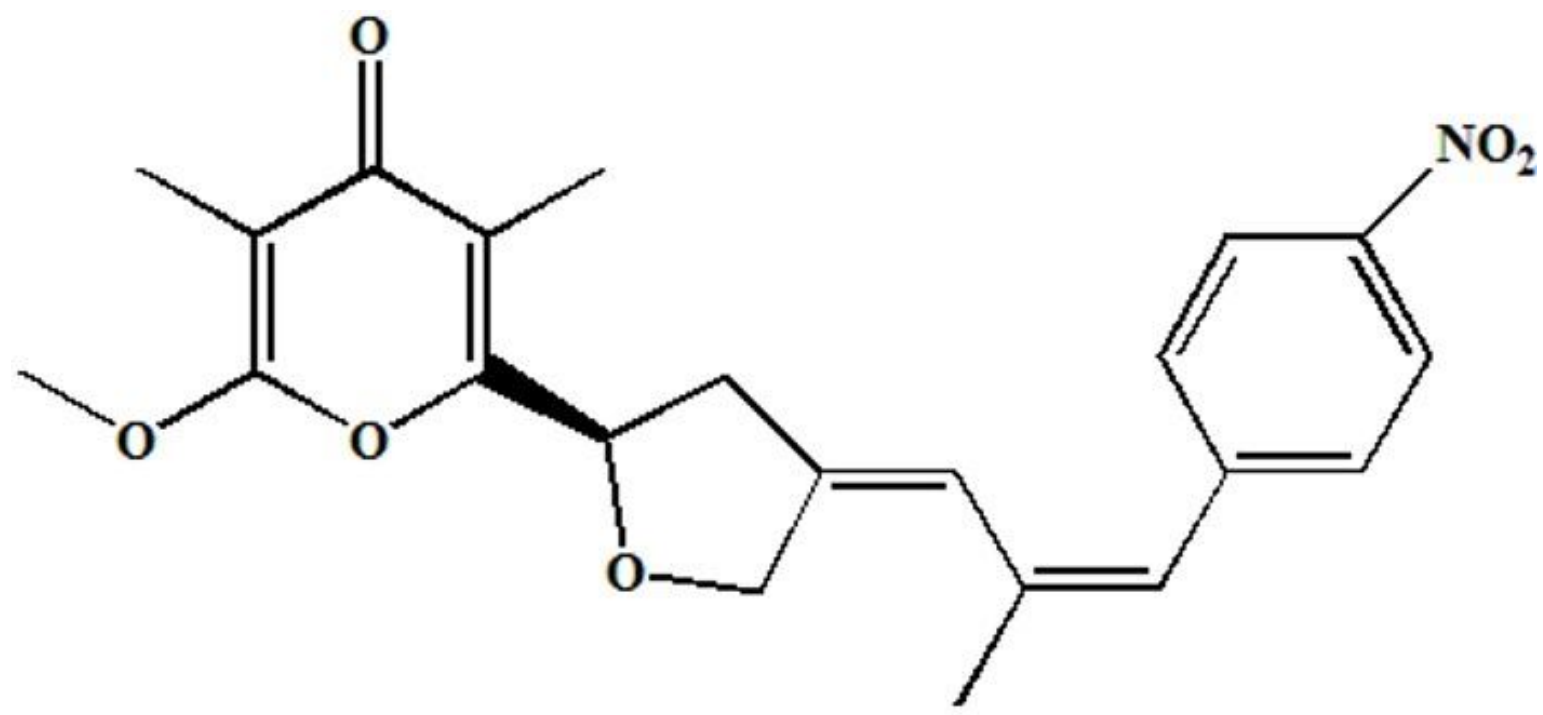

Compound 1: alloaureothin

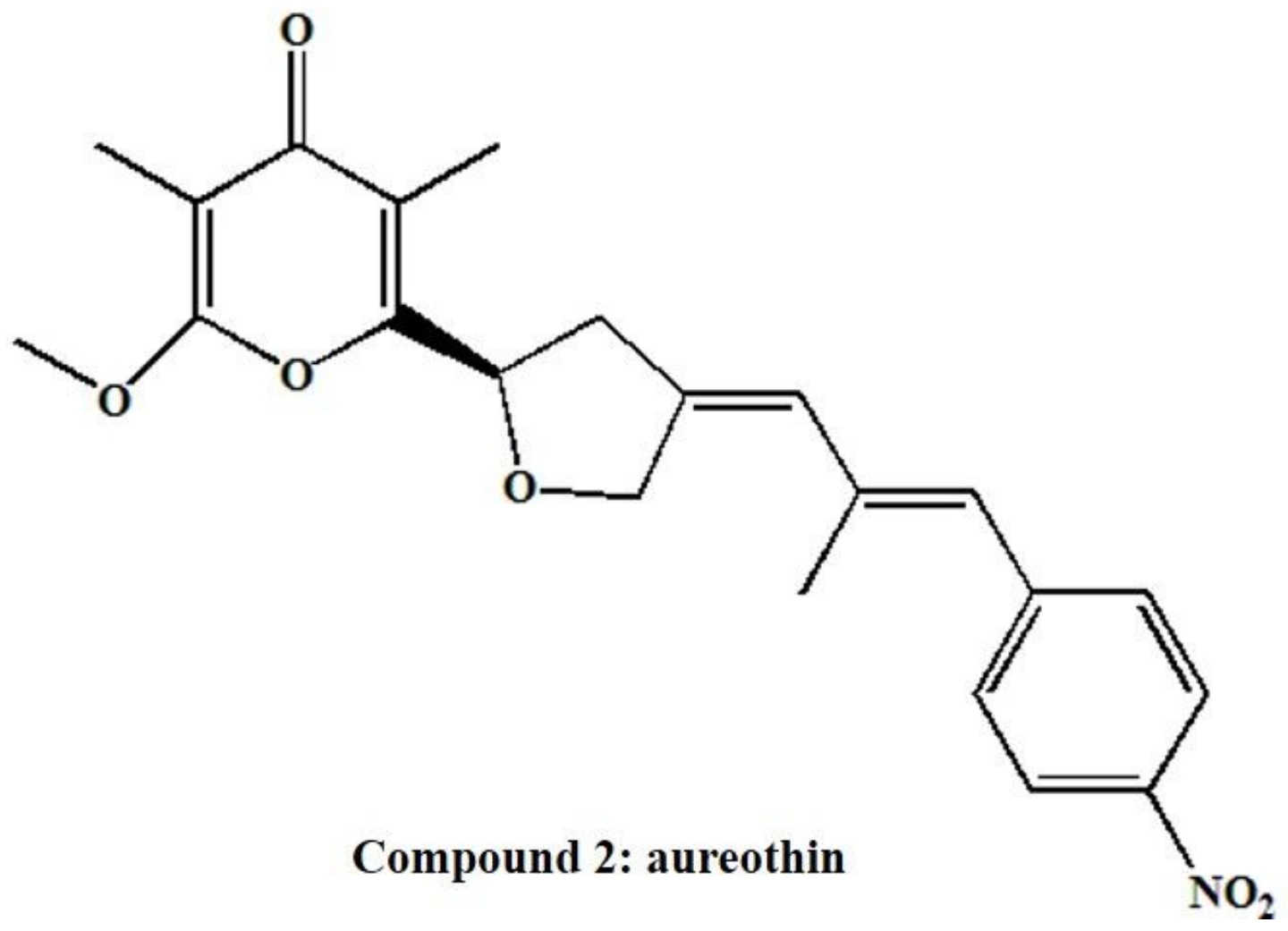

Figure 5

Chemical structure of alloaureothin and aureothin 

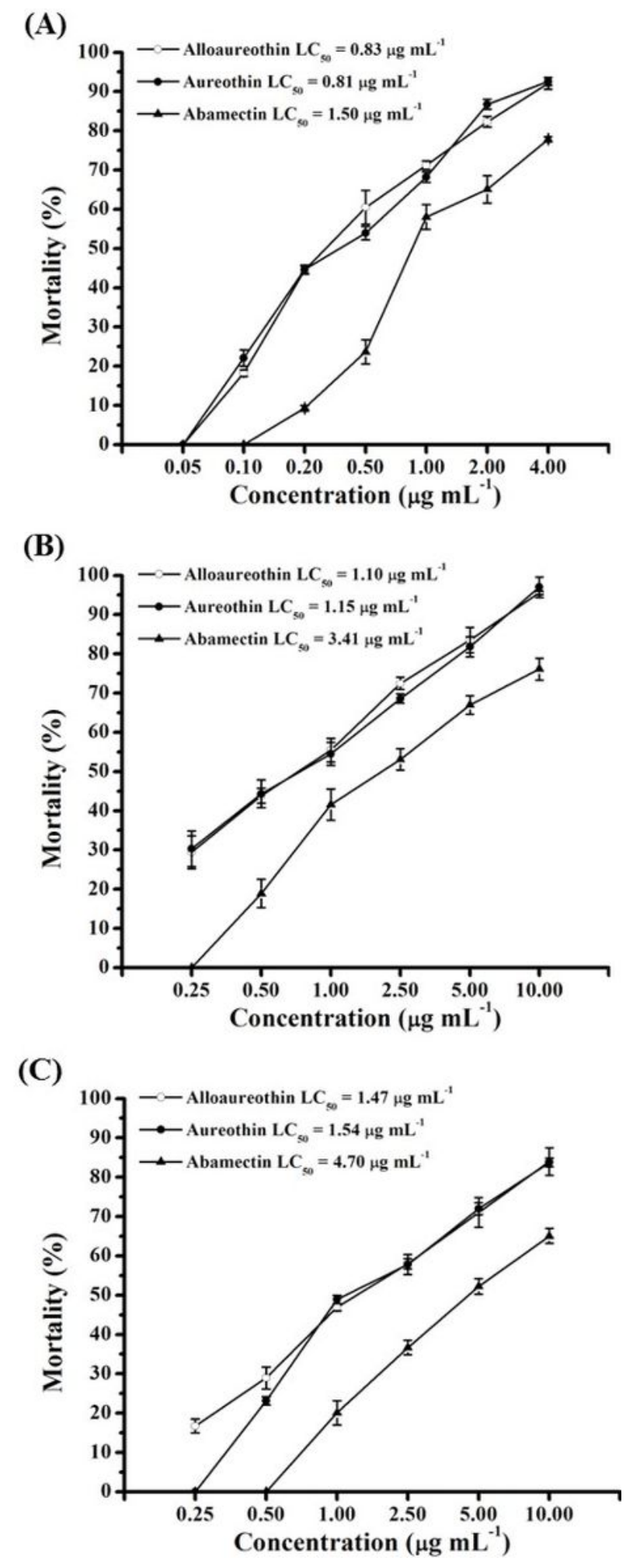

\section{Figure 6}

Nematicidal activity of alloaureothin and aureothin on different life stages of Bursaphelenchus xylophilus after $24 \mathrm{~h}$. (A), L2 stage; (B), L3 stage, and (C), L4 stage/adults. Abamectin served as the positive control and no mortality was observed when nematodes were treated with $2 \mu \mathrm{L}$ DMSO. Data were obtained from three experiments with three replicates each and are shown as the mean \pm SD. 
(A)

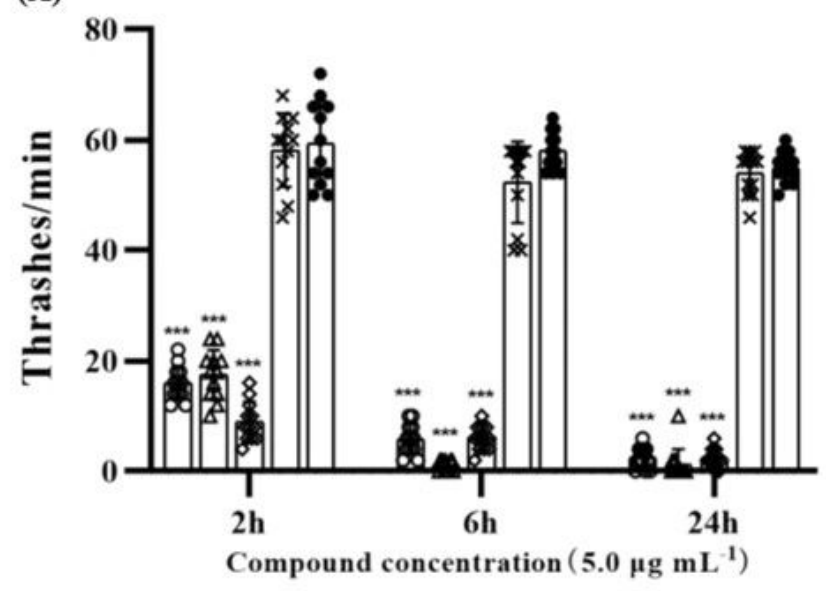

(B)

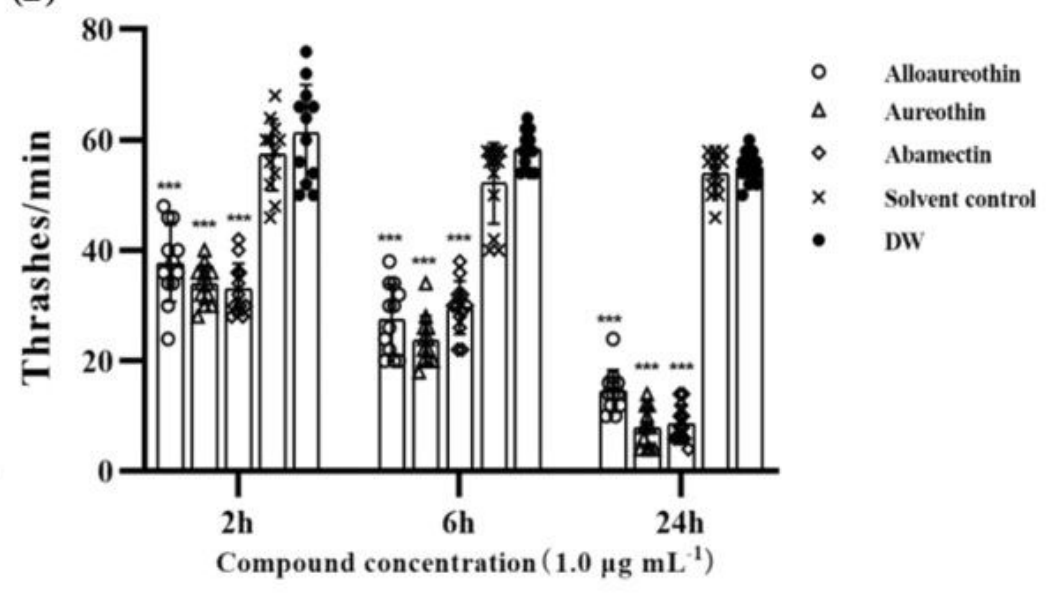

Figure 7

Influences of alloaureothin, aureothin and abamectin on the locomotor activity of B. xylophilus.

Nematodes were exposure to the compound at the concentration of $5.0 \mu \mathrm{g} \mathrm{mL}-1$ (A) and $1.0 \mu \mathrm{g} \mathrm{mL}-1$ (B), respectively. The graphs show the mean \pm SD of two trials with six repetitions.

(A)

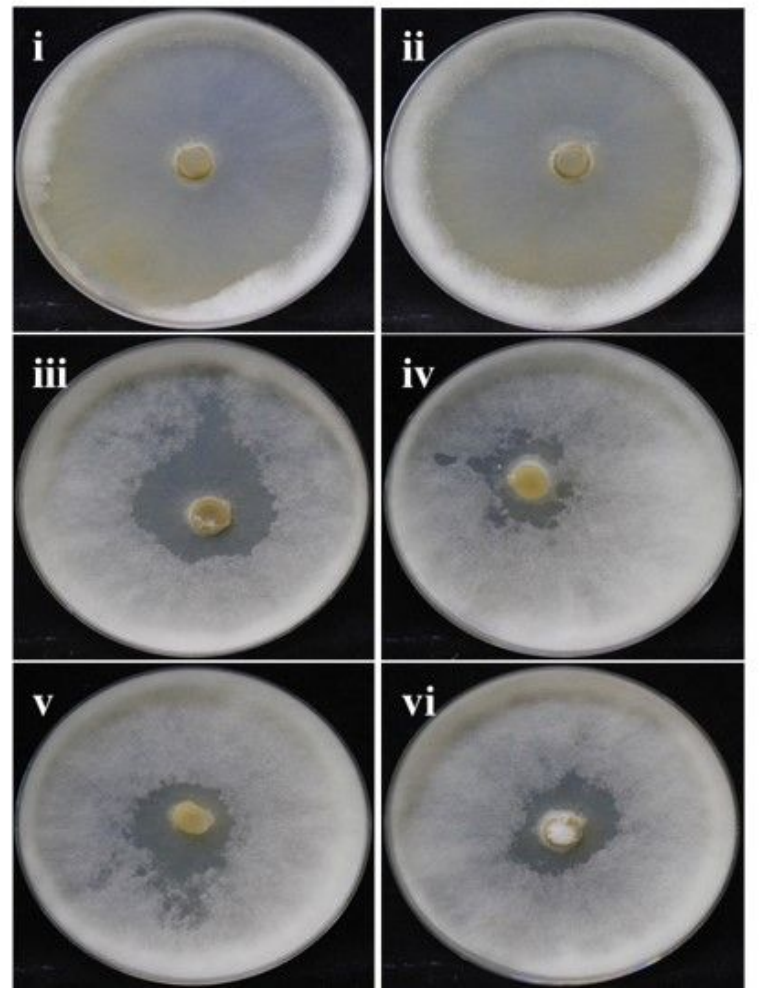

(B)

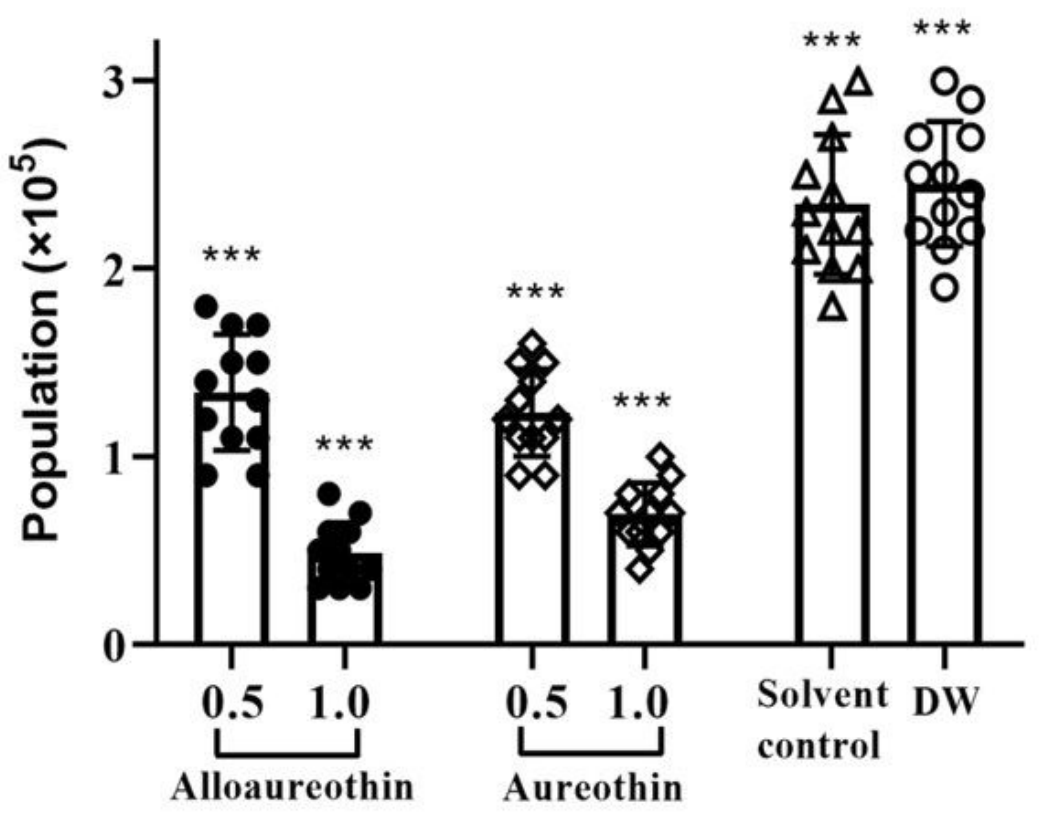

Figure 8

Alloaureothin and aureothin disrupted reproductive traits in B. xylophilus. Botrytis cinerea in Petri dishes after inoculation with B. xylophilus untreated (Ai) or treated with DMSO (Aii), alloaureothin $(0.5 \mu \mathrm{g} \mathrm{mL}-1)$ (Aiii), alloaureothin (1.0 $\mu \mathrm{g} \mathrm{mL-1)} \mathrm{(Aiv),} \mathrm{aureothin}(0.5 \mu \mathrm{g} \mathrm{mL}-1)$ (Av), aureothin $(1.0 \mu \mathrm{g} \mathrm{mL}-1)$ (Avi), and 
the number of nematodes per dish in each treatment were also calculated (B). The results were recored after 7 days inoculation. Values are mean \pm SD of six replicates from two trials.

(A)

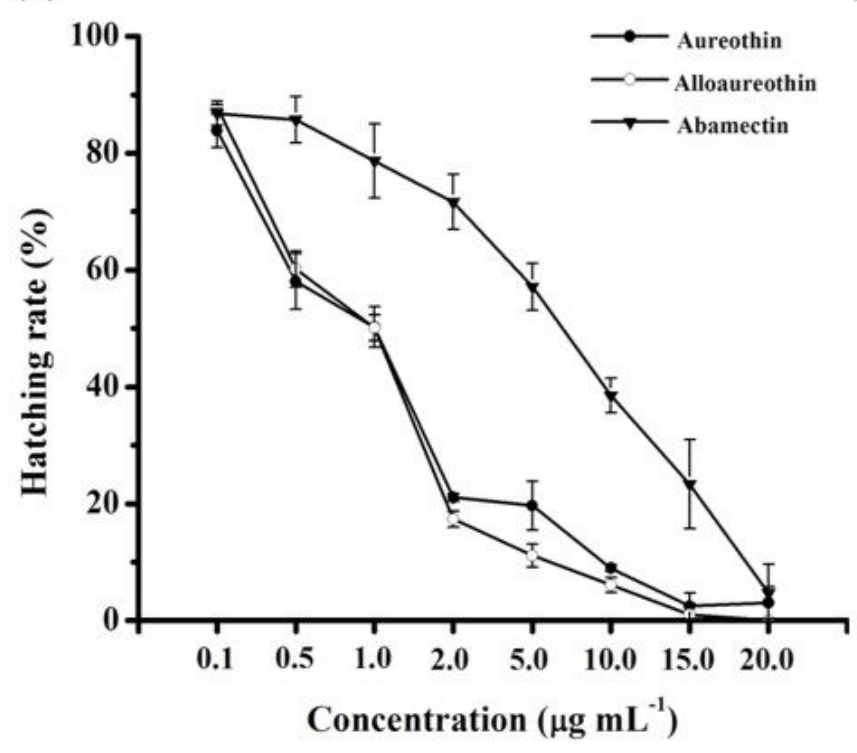

(C)

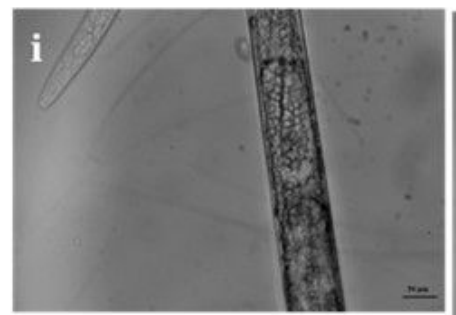

(B)
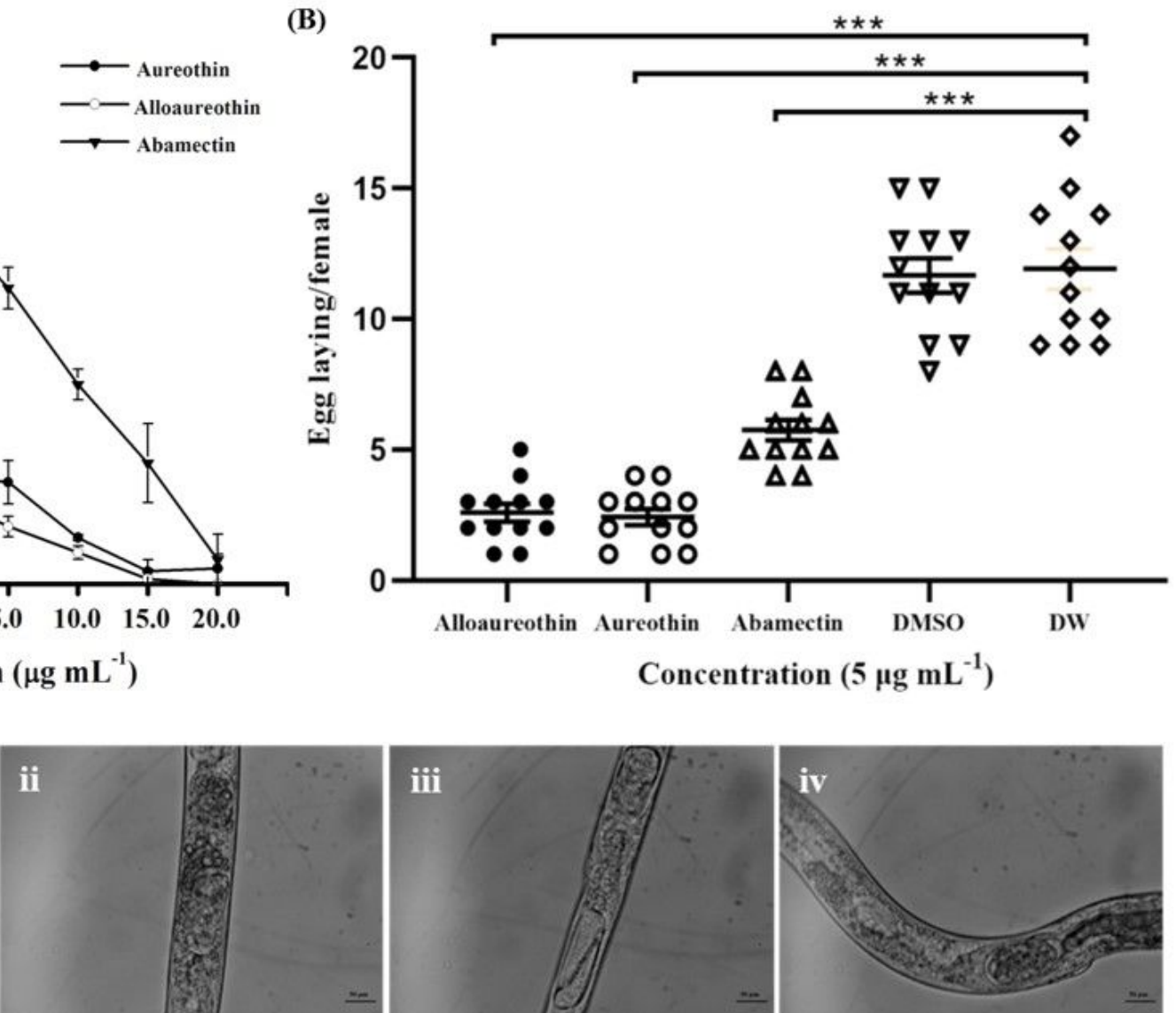

\section{iii}

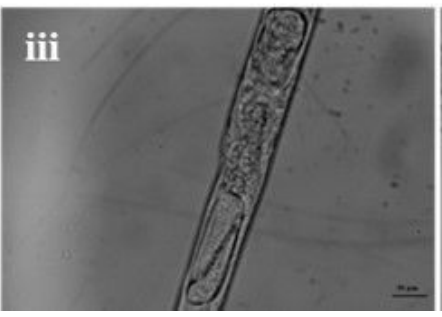

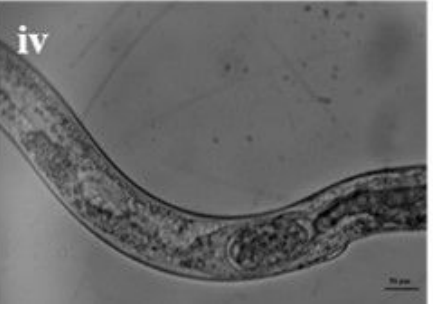

\section{Figure 9}

Effects of alloaureothin and aureothin on egg hatching and egg deposition of nematode. (A) Effects on hatchability after 48 h; (B) Eggs laid by per female nematodes after 24h; (C) Representative images of female nematodes showing eggs when exposure to different compunds [(i) alloaureothin, (ii) aureothin, (iii) abamectin, (iv) DMSO, (vi) none]. Values in graph A are mean \pm SD of three replicates from two trials, whereas graph $B$ shows the mean $\pm S D$ of two experiments with six repetitions. 
(A)
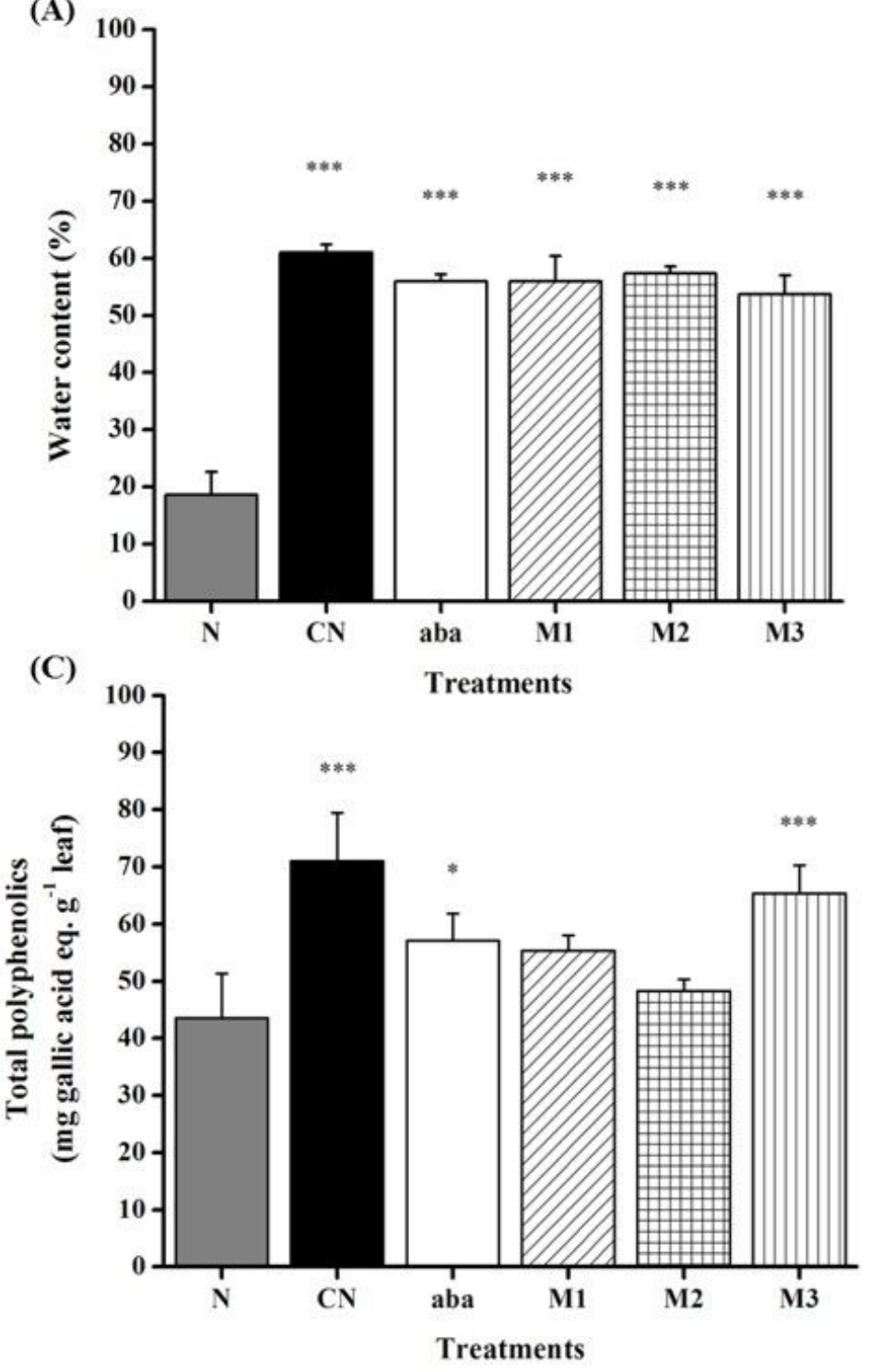
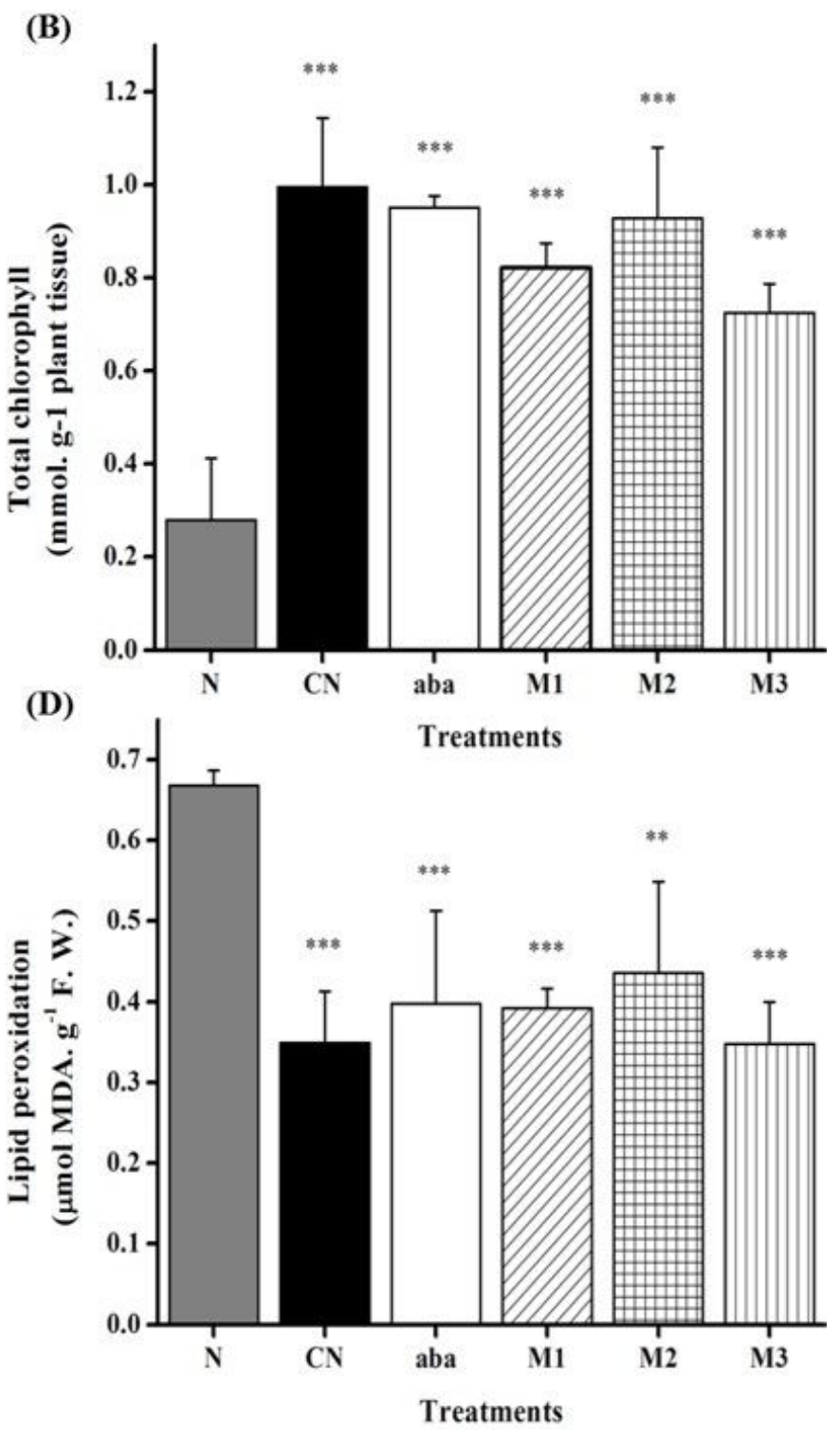

Figure 10

Effect of compound treatments on (A) total chlorophyll content, (B) total polyphenolics content, (C) lipid peroxidation, (D) water content in Pinus densiflora seedlings during nematode infection. CN, N, aba, M1, M2 and M3 represent the same treatments as in the pot test. All the data are shown as the mean \pm SD. 